\title{
Composite preforming defects: A review and a classification.
}

\author{
Rym Azzouz ${ }^{\mathrm{a}}$, Samir Allaoui ${ }^{\mathrm{a}}$, Raphael Moulart ${ }^{\mathrm{a}}$ \\ a ITheMM (EA 7548), University of Reims Champagne-Ardenne, EiSINe, Campus Sup Ardenne, BP50028, 08005, \\ Charleville Mézières Cedex, France. \\ Corresponding author: Samir Allaoui: $\underline{\text { samir.allaoui@univ-reims.fr }}$
}

\begin{abstract}
:
Advancing in the process of extending the use of composites for structural parts applications, it is inevitable to work on complex shapes. That is the main reason why understanding the complex forming mechanisms and the factors put into play during the process of composite materials is a major interest for both pre-impregnated forming and dry fabric preforming. Thus, the apdpearance of defects is a major concern and predicting their appearance for optimal product quality is the priority. A great number of authors showed that defects degrade the overall performance of the composite by creating local heterogeneities. Many factors can initiate these defects. This article is an assembly of the development of the literature on this subject. It is an attempt to provide a description for each defect and a classification order following the scale, the behavior mechanisms, the appearance plan. This will help to converge toward an identification of the defects manifesting during the composite forming.
\end{abstract}

Keywords: Defects, Forming, Fabrics/textiles, Yarn

\section{Acknowledgments:}

The authors gratefully acknowledge the Chair of MATUR for his finnacial support. The chair MATUR is cofinanced by the Région Grand Est (France) (grant number D201507798), the European Union (grant number D201507799) and UIMM (Partners convention n $\left.{ }^{\circ} 13-2015\right)$

\section{INTRODUCTION}

For the last decades, composite materials are more in demand in many industries thanks to their interesting mechanical properties, the possibility of functionalizing them and their good adaptability according to the environment they are used in. To harvest their fullest potentials, one of the challenges to overcome is to master the forming process. If we look at the example of metal forming, it has long been guided by a normalized forming limit diagrams (FLD) or curves. Among the first authors who proposed such approach, we find Hosford and Caddell (1983) who proposed a graphic curves describing the strain limit of the metal sheet in each direction. These forming limit diagrams (FLD) [1] allow determining the formability to know whether a given geometry can be obtained with a specific material. Doing the same for the composite materials is a challenge because having a great variety of composites types along with the highly 
heterogeneous properties make it hard to cover all the variabilities such as the weaving pattern and parameters, the nature and the material of the fiber, the yarn width, treatment undergone such as sizing, conditioning, stress history ... So, it is mandatory to understand the composite behavior during forming. The complexity of the reinforcement brings forwards numerous defects that manifest on different levels. Every factor such as the reinforcement type (fabric type, number of layers, orientation ...), the process type (punch and die, global or sequential stamp, diaphragm ...), settings (speed, tool, pressure, blank holders...) and the geometry (hemisphere, square, double dome, prism ...) can influence the outcome of the preform quality. The effort has been put to understand these defects and the cause of their appearance [2-7] along with suggesting solutions to avoid them [8-11]. It was either manipulate one of these factors or add a new one to oppose the effect of the first. For each application, these defects have been investigated individually. So until today there is no forming limit norm or guide that standardize the forming process for composites. Some authors attempted to preform each fabric with a similar protocol [12] using different type of setting and others conducted benchmark of forming geometries on the appearance of defects [13]. These studies have proven that building a standardized forming limit diagram for composite materials is a challenge. This why a lot of efforts are being put on working on developing numerical simulations [14-16] to determine the feasibility of the forming, to narrow down the factors, to lower the possibilities and avoid unnecessary experimental work. The numerical simulations are a complementary work done before conducting the experimental forming, for side by side verification and validation [17-21]. Alone, they cannot portray all the factors that take part in the preforming, it may show great accuracy but, it cannot be an alternative for the experimental results. The preforming of a composite can be distinguished into 2 types, prepreg forming and the dry fabric preforming, where the defects play a great role in degrading the mechanical properties and creating local heterogeneities and weaknesses that will initiate the failure. To assess the gravity of the defects, many studies have investigated how a defect affects composite mechanical behaviors such as the effect of out of plane wrinkles and waviness on quasi-static behavior [22-27] or the fatigue performance [28, 29], the effect of inplane fiber misalignment [30,31] and out of plane waviness [30], the effect of voids on the composite's limit under compression loads [31] and the effect of the shear angle variation under compression [32]. The literature highlighted that multiple forming defects, on different scales, degrade the mechanical properties depending on their severity hence the importance to predict their appearance. For that, the composite's behavior mechanisms and the multiple factors taking a part in the forming process must be investigated to understand the role of each on the defect appearance. Until now the forming defect studies have shared many common conclusions on this aspect but they did not share the same vocabulary and definition in reference to each of the defects. In this paper, we propose an overview of the different defects appearing during the preforming process that are listed in the literature so far, the different mechanisms associated with their appearance and then a classification depending on their scale (Multi-layer, mono-layer, and down to the yarn defects). This can be the first step to create a composite forming defects manual. 


\section{PREFORMING DEFECTS}

The manifestation of defects during preforming of dry fabric or prepreg forming is a complex process and a result of many factors, either originated from the composite itself (the fabric properties, dimensional or mechanical ...) or the preforming procedure (the preform shape, speed, pressure ...). All these factors should be deeply investigated as they hold the key to understand the phenomena behind the appearance of the defects. Hence, any defect will disturb the homogeneity of the structure creating local variation in the mechanical properties of the composite. Therefore, they are deeply investigated in numerous works in the literature starting from forming a single layer as it is the simplest to study then to preforming a stack of multilayered fabrics adding new variables to the picture. The vocabulary used in the literature is unstandardized from an author to another, all through this article, each time we use the exact term used by an author it will be mentioned between brackets. We propose a defect classification depending on the scale of their appearance: monolayer, multilayer and the yarn/ filament scale. Following the description and definition of each one provided, we can distinguish defects generated due to out-of-plane deformations, and in-plane deformations. The 'plane' referring to the plane in which the fabric takes for its final form after the preform shaped into the geometry that we are aiming to obtain in the final results. Then defects go beyond the change of the fabric form or pattern to appearing on a smaller scale on the yarns or filaments of the fiber.

\section{Monolayers pre-form defects:}

A major number of the studies on the preform of composite materials have been done on a single layer, mostly on forming dry fabric and rarely on Prepreg composites. They used different simple geometries and complex geometries dedicated to specific applications. Using a single layer, defects appear on the level of a single fabric form as an out-of-plane defect or it affects its pattern distribution as in-plane defects.

\section{a) Out of plane deformation:}

One of the first studies was by Tam [33] concentrating solely on the kinematic analysis to form a fiber sheet into a geodesic. Tam highlighted that it is important for the fabric to allow the in-plane shear to prevent the out-of-plane bending, "buckling", where he identified the health of the forming by characterizing the magnitude of the shearing angle in the critical, highly curved areas. Then, he determined that the appearance of the out-of-plane deformation depends on the shear angle. This angle is the rotation that the fabric is subjected to, comparing to its initial direction. In the same period, Christie et al.[34] has attributed the out-ofplane deformation to the effect of the compression (negative tension). When this compression occurs in a certain location of the fiber alignment, the fabric buckles in an out-of-plane deformation. They concluded that this phenomenon depends purely on the stress distribution in the concerned area, which is very complex in the case of composite forming, highlighting that building a forming limit diagram like for metal sheet forming dictated by Hosford and Caddell in 1983 is a challenge. This limit is a criterion defined by the formability, which is the ability of the fabric to take the shape and form of defined geometry and undergo plastic 
deformation without creating any damages [35], which is measured by conducting different tests. The higher the curves and the details, the higher the formability is required.

Yu et al. [36] identified the different deformation modes of fabrics: transverse compression, out-of-plane bending, in-plane tension and in-plane shear. They suggested that by conducting these tests we can determine the formability of the fabrics. They used different types of fabrics and measured their shearing angles and their behavior in different deformation loads experimentally. They concluded that the formability depends strongly on the fabric type that is why there were authors who build on their statement and investigated the effect of the fiber type on the fabric behavior during preforming. Mohammed [37] studied 4 types of fabrics (Fig.1), under the same forming settings, formed all into an identical hemisphere. The fabrics have shown different characteristics of out-of-plane deformation ("wrinkles"). As an example, certain types of reinforcements such as the plain weaved fabric have a more liberated angle rotation so it can resist wrinkling compared to the tight weave and satin. The appearance of this defect was explained by being a result of the compressive loads, created during the forming, as it is subjected to shearing to conform to the punch shape. A buckling deformation manifests out-of-plane of the fabric's thickness when the strain energy is too high for shear to absorb it, thus surpassing the locking angle and creating a double curved shape. The "locking angle" is defined as the onset angle of the out of plane deformation where the fabric is sheared at a certain state with an in plane yarn/yarn compression leading to an energy in which the fabric cannot accommodate, so it deform into a new form/shape to dissipate and cancel this energy by forming out of plane curve as "wrinkles".

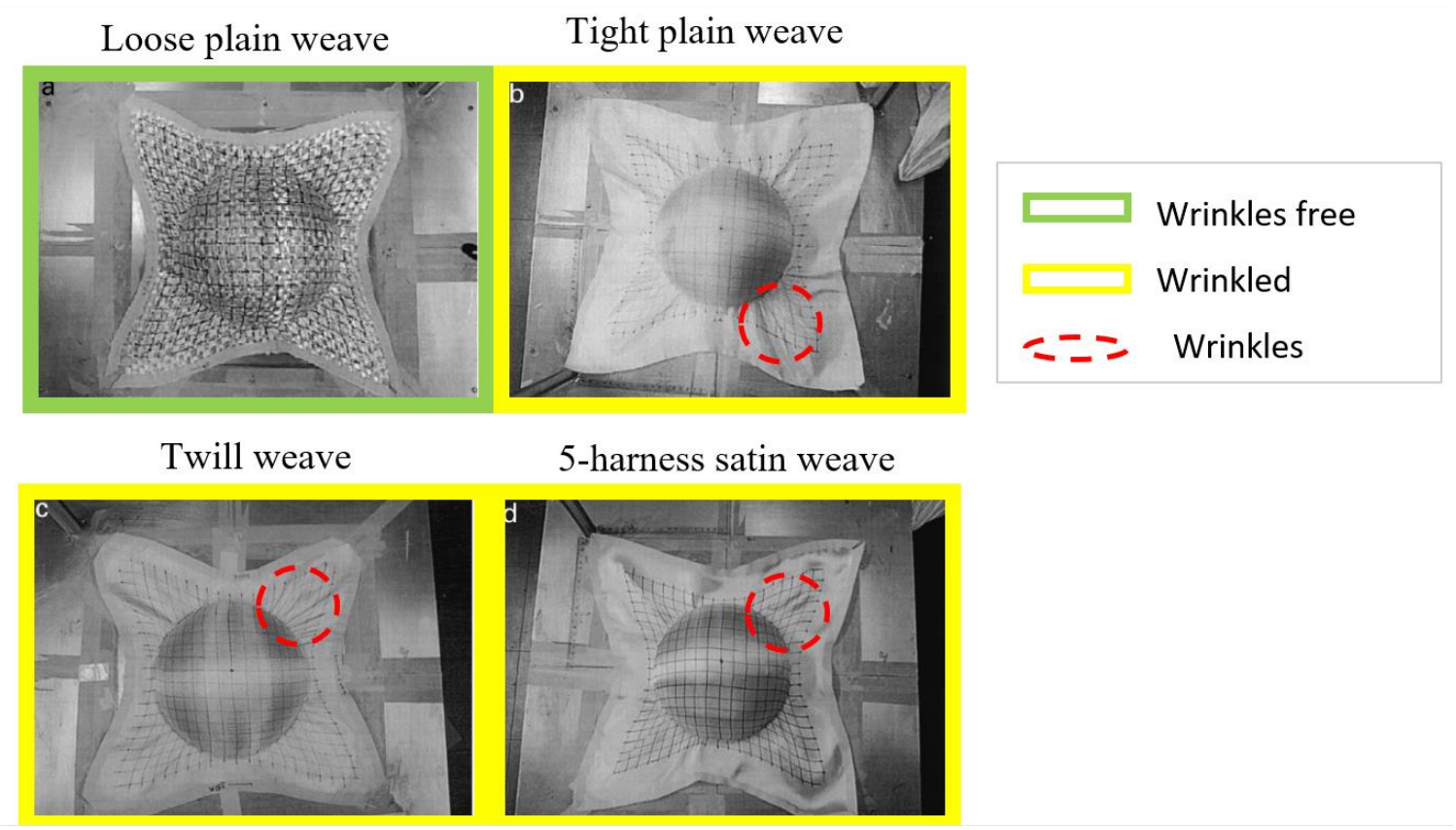

Figure 1: Wrinkles forming loose plain weave, tight plain twill 5-harness satin weave formed into hemisphere 
For almost a decade, the out-of-plane deformation was attributed to the shear and tension behavior of the fabric. This was the earliest concentration of Boisse's work [38] (Fig.2) where they studied different types of fabrics: First, by identifying numerically and experimentally their tension stiffness in the weft and warp directions, then implement it to the model set into 2 forms(a hemisphere, a square). For the result of the simulations, the areas with high shear angles are compared with the locking angle determined experimentally. Starting with the tension approach only, the rotation of the in-plane angle has no limit. Thus, no out-of-plane deformation occurs even in highly unrealistic angles' deformations. Later in [39], he highlighted the importance of the shear stiffness, as a fabric property, to predict its behavior during forming [40]. He showed that taking the shear stiffness into account allows the wrinkles to appear in the final result of the simulation when it surpasses the locking angle where wrinkles are initiated to reduce the energy of the shear strain. As a result, we have more accurate and realistic results compared to the simple tension model, especially at the point when the "locking angle" or the "shear limit" is surpassed.

\begin{tabular}{|c|c|c|c|}
\hline a-Experimental forming & b-Tensile rigidity only & $\begin{array}{c}\text { c-Tensile and in-plane } \\
\text { shear rigidities }\end{array}$ & $\begin{array}{c}\text { d- Tensile }+ \text { in-plane }+ \\
\text { bending rigidities }\end{array}$ \\
\hline & & & \\
\hline & $\begin{array}{c}\text { A great number of small } \\
\text { wrinkles }\end{array}$ & \\
\hline
\end{tabular}

Figure 2: Different modeling approaches comparison, a- experimental forming , b-tensile rigidity,c-tensile+ in-plane shear rigidity,d- tensile+ in-plane +shear rigidity+ bending rigidity [41]

The wrinkles were illustrated and their location agreed with the experimental results (Fig.2), but the shape is reduced to small wrinkles with almost equally distributed magnitude. Boisse [41] suggested that these properties are not the only ones contributing to the wrinkles manifestation. So, the third propriety proposed was bending stiffness, which was previously proposed and characterize by De-Bilbao and al [42] on several fabrics. He proved the importance of implanting the bending stiffness to illustrate the preforming behavior, especially in profiling the wrinkles. The possibility of the out-of-plane deformation is higher compared to its ability to resist the in-plane shearing and maintain its position because the energy needed to deform out-ofplane is much lower. That is why the first form, which is taken by the fabric, to alter the compressive loads in wrinkling is by forming a double-curved shape. By doing so, the compressive strain energy is dissipated and lowered. Authors proposed using a blank holder to apply opposite forces on the yarns network. The applied pressure increases the threshold of the compressive energy needed to trigger the out-of-plane deformation, 
which decreases the risk and delay the wrinkles formation until angles beyond the locking angle . It is also proven that the properties of the wrinkles, such as number and magnitude, depend on the bending stiffness of the fabric [43][44] where the magnitude of the wrinkles increases along with the bending stiffness. So to oppose the bending energy from acting up and triggering the out of plane deformation, it could be nullified by adding opposing tensile energy into the picture, transferring all the energy into shearing. So we can have a delayed onset of the out-of-plane deformation with shear angles being higher than the locking angle, so we have a delay in the appearance of the defect.

So, adding the bending stiffness to the tension, the locking angle is not a criterion for the existence of the wrinkles. This statement was subsequently backed up by the result found in other studies where the onset of the wrinkles can happen at higher than the locking angle [37] or be avoided even with widely exceeded locking angle [45]. This questioning the certainty of the first definitions of the locking angle in 1993 by A.C Long [46] and later in 1998 by J.Wang [47], where it was measured by an experimental shear test (picture frame and bias test) assuming that there is purely in-plane shearing, whereas the appearance of wrinkles is driven by a strong coupling between shear, tension and bending behaviors. Many studies proved that the locking angle is relative to the process, depending on all the different properties mentioned above, coupled to shape the result accordingly. Thus, one by itself is not enough to set the deformation mechanism during the preforming. So the idea suggested earlier during the '90s by Yu et al. [36] to determine the formability by performing separate tensile, bending and shear experimental tests is not enough, because during forming, the fabric is subjected to all these modes of deformations at the same time and they can be coupled. As a result, some of these modes may magnify or cancel the effect of each other, so they play a major role in determining the final shape, state and location of the out-of-plane deformation. Thus, independent mechanical testing is not enough to cover the full picture of the forming behavior. That is why, to predict the formability of a structure, implementing the mechanical properties into a numerical model, seems the right solution. But, to be so, it has to cover all the variables during the forming, from the forming process setting to the fabric properties, the form geometry, etc., which is in reality very complicated due to the interfering of different factors and acting at the same time. So the numerical simulation results until this day are accurate and satisfying in term of presenting the out of plane deformation and predicting their appearance and profile (magnitude and number) .

There has been almost no major addition since later the authors focused their efforts on investigating which factor is associated with each deformation mode aiming to understand and prevent the out-of-plane deformation from manifesting. One of the methods is to optimize the blank holder pressure, used as a tool to maintain the sheet's initial position during forming. The blank holders apply in-plane tension, which opposes the compression stress that is one of the main causes of the initiation of wrinkling. Authors like Allaoui [6][45], on interlock shaped into a prism and tetrahedral, and J.S.Lee [7], with NCF shaped into a hemisphere, studied thoroughly the effect of varying the blank holder pressure, even with different fabrics type and 
geometries. It has been proven that the blank holder plays a major role in delaying of the wrinkling helping to suppress the compression stress.

The authors also worked on the variation of geometries and their influence on the out-of-plane deformations. They have found that when the geometry holds a highly curved shape or small radii, it creates additional stress in that specific local area that forces the fabric to adapt to the distinctive form of the geometry. There is a limit to this adaptability [48], it can end up with wrinkles [8,45] or in rare cases with bridging [49-51]: it is when the fabric is not able to copy the radii of a corner of the geometry with it will maintain a bigger radius, thus a void between the shape and the fabric in this local area occur. It is also found that the wrinkling can be delayed by using the punch and die vacuum bag, which creates normal compressing making the energy needed to deform out-of-plane more important, thus resisting and maintaining its plane form for longer. But these solution has to be conducted with caution because by applying excess pressure in the case where the wrinkles are already formed, we can create "folds". In fact, after the forming of the wrinkles if any pressure is applied, one of the two sides of the curved wrinkles will fall on the second and create a local fold with 2 more extra layers, so further complicated defects (Fig.3) [49][4].

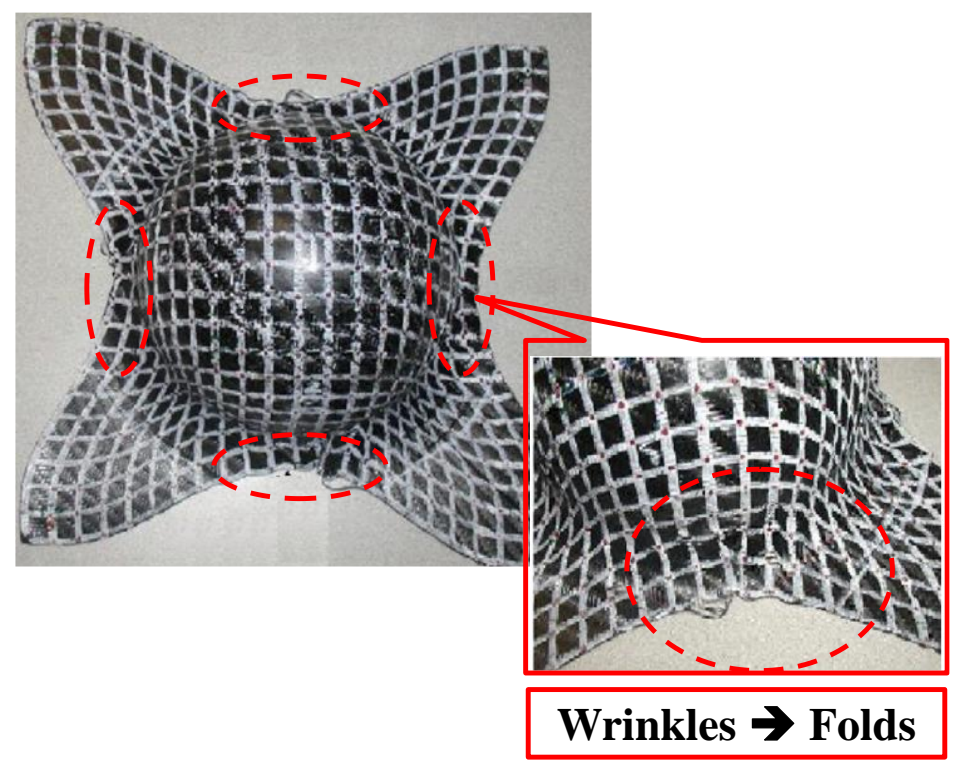

Figure 3: Details of the occurrence of wrinkling turning into folds [4]

Even though the pre-impregnated has rarely been studied a single layer [4, 52], the out of plane deformation mechanism is identical with a difference due to the presence of the resin which, when heated, acts as a lubricant due to its viscosity leading to reduce fiber / fiber friction. This lead to a decrease of the stress state of the reinforcement, and therefore potential defects, as the friction is the predominant mechanism of the fabric behaviors (shearing, lateral compaction, bending, etc.), due to its heterogeneity, where the movements of fibers, yarns or ply occur. Putting on the spotlight another parameter investigated, the friction manifested between the tool and the reinforcement [53][54][55], which was not taken into consideration before. This 
friction creates an adding tangential load on the fabric, which should be taken into account for how it can contribute to wrinkles formation.

\section{b) In-plane deformation:}

In addition to the out-of-plane deformation, the fabric has the liberty of an in-plane movement. For an inplane defect, the fabric pattern changes leading to local heterogeneity. When a single layer is subjected to inplane strain, the pattern is affected to adapt the shape and the risk of defects is high in many cases (depending on the geometry, the fabric, and the process settings). Laroche [56] was amongst the first that explored the effect of the shear angle "variation on the thickness distribution", which can be considered as a defect while testing six different types of fabrics. The preform geometry is highly curved on top with a radius of $60 \mathrm{~mm}$. The author developed a geometrical equation that represents the thickness increase due to the shear angle in one cell, using the volume conservation assumption. This study showed that the final thickness can exceed 1.4 of the original fiber thickness in a high sheared zone. This variation in fiber density creates heterogeneity in mechanical properties. This form of defect is due to the shearing behavior that manifests by yarns rotation. Hallander [57] identified three distinctive defects in the unidirectional laminate prepreg composite. The first, called "the fiber angle variation" is when the fibers keep being parallel to each other but change the direction of their alignment (Fig.4-a). The second type is an "in-plane waviness" (Fig.4-b) where the compressive load in the same direction as the fiber results in an in-plane buckling, in the form of waves, losing the fiber's initial linearity. And the third type is a "spreading or tightening of the fiber tow" (Fig.4-c) where the fibers lose their parallelism. These defects influence the fiber distribution and orientation in the structure and lead to local variability of the fiber density and thus areas rich in resin after injection. This heterogeneity affects directly the mechanical properties which depend strongly on the fiber direction, orientation and density[58][59].

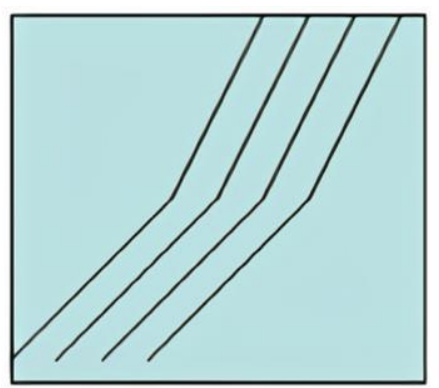

(a)

Fiber-angle variations

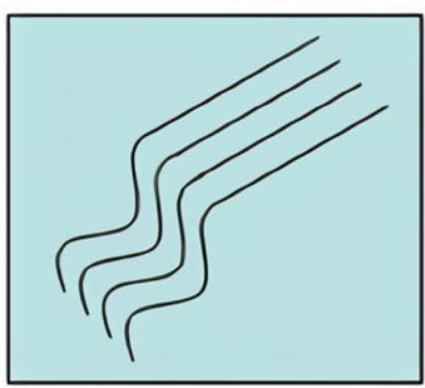

(b)

local fiber angle variations (in-plane waviness)

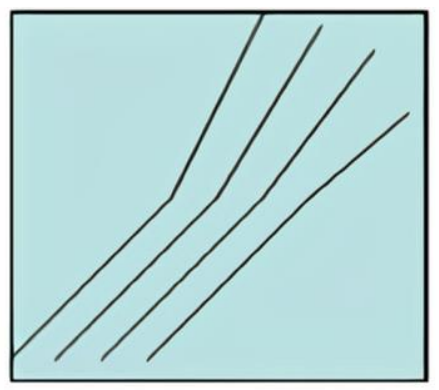

(c)

Spreading or tightening of the fiber tow

Figure 4: In-plane deformation modes a- Fiber angle variations, b- Local angle variation c- Spreading or tightening of the fiber [57] 
For the fabric, not only rotation is allowed under strain but also an in-plane sliding displacement between the yarn/filament of the fabric. So, yarns can slide in a transversal motion and stay parallel to their initial direction (their network). The motion can be homogenously distributed all along with the fabric. This defect is manifested as a consequence of the load distribution and fabric movements. This displacement can occur in both directions: when the yarns or the filaments move perpendicular to their initial position and stay parallel [49] (Fig.5-a) or when they move parallel to their initial position and stay in the same direction in a pulled out or pulled-in motion in the longitudinal direction (Fig.5-b) [60][61]. This defect manifest when the in-plane tensile is higher than the cohesion forces (mostly due to friction), can alter the unit cell dimensions and create local high and/or low-density areas. When the density is low, the defect is considered as a "gap"[59], which hinders the resin injection process with variability in the permeability resulting in resin-rich and resin-poor areas. The outcome will be a weak mechanical performance. Since this behavior depends strongly on the fabric cohesion, the type of reinforcement influences the outcome of the sliding phenomena.

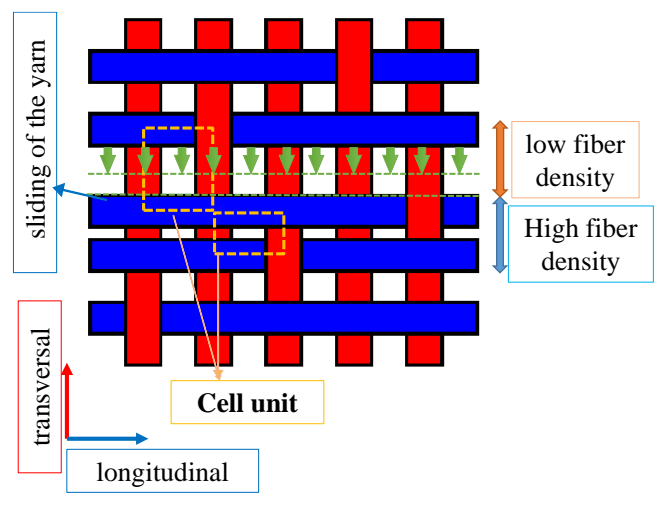

a) Sliding (transversal)

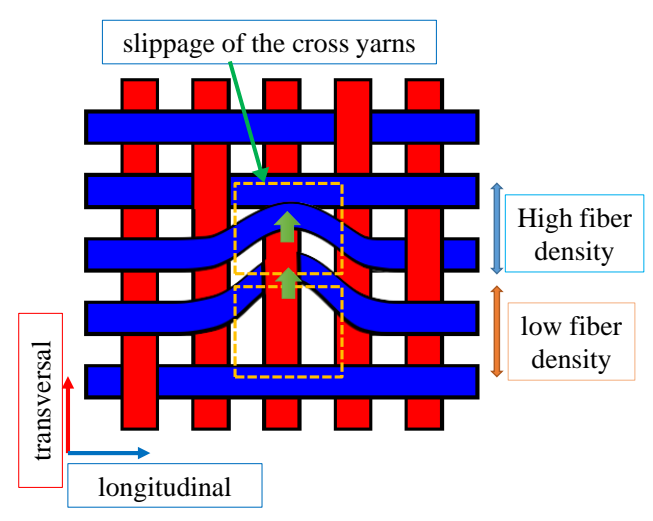

c) Slippage

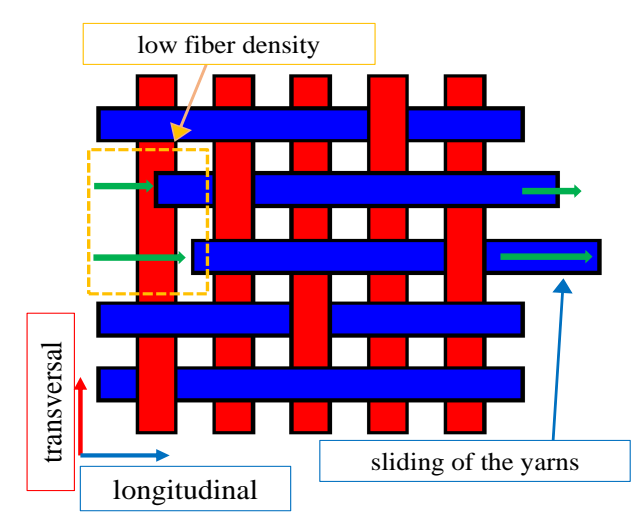

b) Sliding (longitudinal)

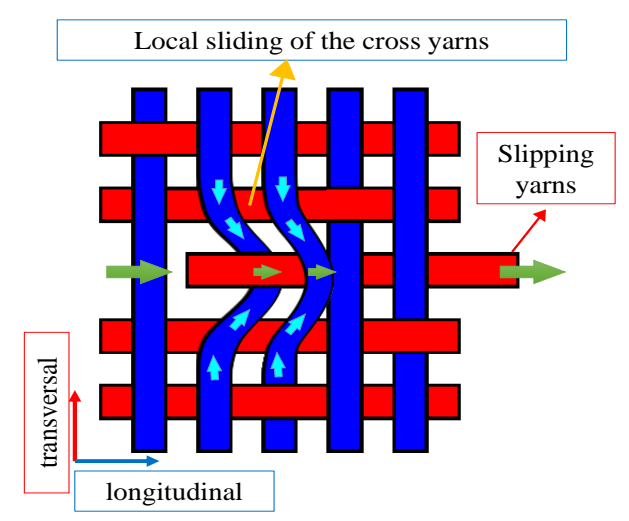

d) Longitudinal sliding + slippage

Figure 5: Sliding and slippage defects 
Thereby, these defects are most likely to occur with the unidirectional or NCF [48] or the unbalanced fabric [39][62] where the friction and cohesion are not equally distributed in all directions or asymmetrical. This defect has been called both " sliding "or "slippage" or both and also called "fabric shifting" [8]. For this particular defect the direction of the yarn or filament movement can be transversal or longitudinal, but what is in common is that this "sliding" affects the latter in a homogeneous way all along with the fabric.

The previous defect can be created locally when the linear form of the yarns is lost and a particular zone slips from its previous direction in a transversal direction forming an in-plane local curve (Fig.5-c). The causes are numerous such as compression, bending or tensile that can be generated due to a local detail of the preform that forces the fabric to take a curved shape (as an example: a hemisphere's curve [37], prim top [53] or tetrahedral side corner [54]) and force the fabric to slip to accommodate the change in the length. It can also be caused by the fabric maintaining system used during the pre-form process like blank holders, clips and springs [2] or by an error in the fabric handling before the preforming process. One of the major reasons behind creating this defect is the "sliding ", which is described previously. When yarns slide in the longitudinal direction, the effort applied to them is higher than resistance forces, due to the reinforcement cohesion, that they encounter which are located at the intersections with the yarns of the other network. If these resistance forces are locally higher than the other region of the fabric, the concerned transverse yarns are carried along locally, so they slip creating an in-plane curve (Fig.5-d), thus creating a local "slippage" [65]. This causes a drop in the local fiber density, so low that it is considered a "gap". This defect has been also called in the literature by "laddering" [8] and "weave pattern heterogeneity" [45].

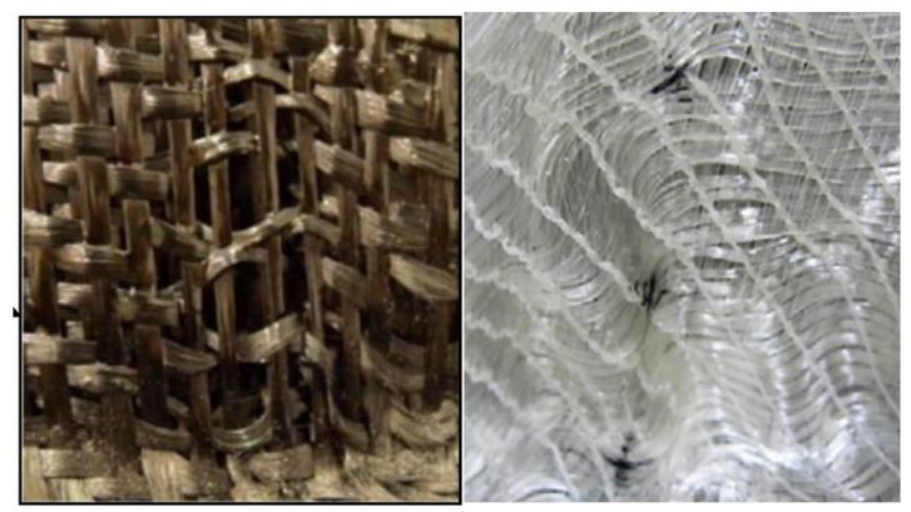

(a)

(b)

Fig 6: Fiber buckling :a-[45],b-[7]

In some cases, these pattern disturbances can be highly irregular and look seemingly random due to the coupling of different in-plane deformations like the defects mentioned above that are concentrated in the same area. This generates a disturbance in the pattern and changes the structure of the unit cell. This defect has been referred to as the in-plane "buckling"[45] (Fig.6-a), fiber displacement [9] [7] (Fig.6-b) and occur when the yarns are subjected to coupled stresses (compression, bending, shearing, ...). This lead to yarn buckling, due 
compression force, which is very heterogeneous because of the local heterogeneity of the comression stresses. In parallel, the tangential force, that are higer than the fabric cohesion forces, lead to slippage that affects a group of unit cells leading the fabric architecture to lose its uniformity. These coupled forces can be generated by severe details punch geometry that requires the fabric to sustain a combination of modes of deformation. The profile of this defect depends on the characteristic of the material, and the distribution of the forces behind the deformation mechanism, amplitude, curves directions.... Later, their moving direction is dictated by the stress distribution and the process parameters consisting of the blank holder pressure, tool/fabric friction and geometry.

\section{2) Multi-layer preforms defects:}

The out-of-plane deformation for the multi-layer configuration is like the single layer in terms of the mechanical phenomena with additional variables, which are the layers stacking, number and thickness...

\section{a) Out of plane deformation:}

One of the most basic, yet critical, types of forming is bending the structure to a predefined angle. Due to the radius change of the different layers of the stacking that is funcition of the value of the bending radius of the punch, the radius area is considered a critical area with high defect risk that must therefore be investigated. One of the earliest studies was by Tam. A.S [66] on bending the prepreg thermoplastic composite into V-Shape, which resulted in the appearance of an undesired feature defined as "Buckling" (Fig.7 -a). This defect is a result of having different radii at the corner, enhanced by the thickness of the preform and the inter-ply friction, which applies compression leading to buckling on the inside surfaces. During the bending of the corner, the ones closer to the interradii can develop an excess of length that cannot be dissolved easily through the length because of the inter-ply friction. With an excess of material's length and the compression load applied by the tool geometry to force the fabric to adapt to its shape, the outer layers deform out of plane and buckle. Hallett referred to this default as wrinkles [20, 30, 67] (Fig.7-c). This defect severity is strongly influenced by the thickness of the plies [68] proven by J. P.-H. Belnoue et al. while developing a numerical model to include the effect of different factors, geometrical, material properties and process parameters. Recent authors have investigated the way the wrinkling manifest during the forming process and develop [69]. Tam et al. suggested applying a tensile load on the interior plies, during the forming process to oppose the compressive load, to avoid the forming of any buckles on the corner. Other factors influence the quality of the preform such as the speed of preforming that induces poor surface quality, or the temperature distribution between the punch and die throughout the thickness of the preform, the position of the wrinkles is either side of the corner, the inter or the outer side depending on the geometry characteristics, and it is concave or convex. J. P.-H. Belnoue et al. [68] stated, in their work comparing the laminate in contact with the tool at the external radius and or a trapped laminate below hard tooling, that the wrinkles are influenced by the inability of the prepreg to compress or slip, the access length is generated in the form of the out of the plane deformation. Similarly, Cattanach [70] defined two corner default mechanisms. The first one is the same as the buckling mentioned by the authors above and the second one is defined as a "resin 
squaeezing". This last consists of a resin-rich area at the outer corner (Fig.7-b) that appears when the external ply surface is subjected to tensile load forcing the fabric layers to squeeze in the interior section on a smaller radius and the resin to get out. The resin squeezing and the buckling default can also be a result of an attempt to reduce the buckling on the inter corner by applying a tensile load on it as suggested by Tam. This phenomenon was also investigated by L. Jerpdal [71].

a-

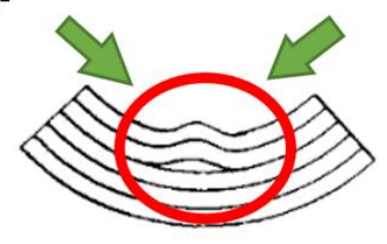

b-

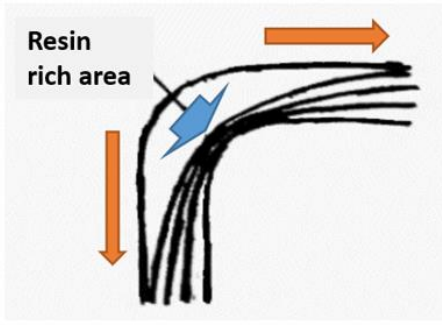

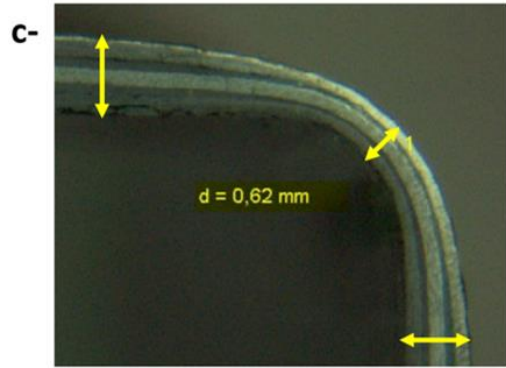

Figure 7 : a- Buckling [66] , b- Resin squeezing [70], c- Thickness variation [75]

Another defect has been investigated which is the thickness reduction and volume fraction variation on the corner that influence dramatically the uniformity of the geometrical and mechanical properties of the structure. Hubert et al. [72] determined that the thickening of a corner tend to occur with a concave tool contrary to the convex shape that induces the thining explained by two different mechanisms in their later work [73]. The first being the corner/flange pressure variation, where the resin accumulates and flows to the corner due to its locally low pressure[74] and the second being the inter-ply friction. Hallander et al. [75] determined the influence of the interlayer friction by changing the fiber orientation and implanting a veil on the outcome of the forming procedure of the unidirectional (UD) laminate composite with mixed ply materials formed into the C-channel. The thickness variation at the corner with and without an interlayer veil, showed the importance of reducing the friction between the layers at the corner, similar to that described by Bickerton [76] (Fig.7-c) who worked on the dry fabric (woven carbon fiber and a stitched fiberglass). Bickerton found that the thickness is at its minimum at the corner tip, reducing the space between the fabric tows and forming an obstacle in the face of the resin flow, thus, affecting the local permeability, which is studied S. Pierce [77] in their work where they determined the effects of the variation of the reinforcement shearing on the permeability while building a numerical model to predict the resin flow behavior.

Besides the defect appearing on the corner, Hallander et al. investigated in their later work [57] the influence of compression on the out-of-plane defect for the UD prepreg multi-layer forming, resulting in the fact that these defects can reduce the strength up to 40\% [78]. They have defined two out-of-plane defects: "Waviness" (Fig.8-a) and "wrinkles" (Fig.8-b). These defects are due to the loss of fiber linearity (in-plane), due to the compressive loads, giving it an amplitude in the out-of-plane direction. Both the waviness and wrinkles 
present the same phenomena that result in wrinkles with severe amplitudes and waves with a lesser amplitude. These defects can appear from the first layer reaching the last one or they can start at any level and build up from one to another, depending purely on the compressive stress applied on each layer of the stress from a neighbor layer. These defects (waviness, wrinkles) have been highlighted by multiple authors. One of the earliest is Haorong, L. I., \& Gutowski [12] in 1997. They attributed this phenomenon to the inability of the material to cope with the shear applied in an area. The material on its own has a degree of resistance to absorb this shear until a threshold level in which the shearing mechanism is prohibited leading to failure thus the initiation of wrinkling. In this study, they introduced a form of "forming limit diagrams" for composite forming aiming at detecting the laminate wrinkles initiation. They studied the effect of different factors like the number of plies, the orientation, the diaphragm tension, the compressive forces, etc. By the same year, Ó Brádaigh [79] investigated the same type of defects but used the term "shear buckling" and they described it using two different forming procedures: the forming using Huang et al. and the diaphragm forming. The following year, DeLuca et al. [80] published their work on the PEEK resin reinforced by UD carbon fiber layered up in 20 layers within different orientations. They studied the effect of the use of a blank holder and concluded that using blank holders to apply tensile force on the edges while forming can delay and reduce the appearance of wrinkles on the top layer. Later, the majority of the authors identified the out-of-plane defect as the "wrinkles", such as Thije R. et al. [81] who added the definition of the "folds" for the multi-layer preforming. This "fold" identified by Lisa M. Dangora [44] starts with the formation of out-of-plane waves. With a higher pressure, the distance between the two sides of the waves starts to close until they collide, to adapt to the form forced by the punch, thus creating a fold to end up with a local area where the number of layers and thickness is doubled. For the multi-layer preforming, the profile of the wrinkles as the size and number has been studied latterly by Boisse et al. [82] with the main factor influencing that is the bending stiffness and Huang et al. [83] taking into consideration the role of the excess length in initiating the appearance of wrinkles where they proved that the amplitude differs from layer to layer due to the variation of the outer pressure on each layer and the orientation of the woven fabric.

As concluded before, investigating the influence of factors like the blank holder's pressure, orientation settings and layup, fiber type and geometry helps to identify and predict the location of the out-of-plane deformation. Each different forming process is characterized by its own set for variables. While forming the prepreg composites additional factors join the picture like which is the temperature distribution. As mentioned by Wang [3, 84], it is essential for an ideal thermoforming to have an isothermal and homogeneous temperature distribution in the prepreg stacks. It is hard to obtain this during the forming process and this creates a temperature gradient between layers. As the viscosity and stiffness depend on the temperature, the mechanical behavior will be different from one level to the next, which initiates the appearance of wrinkles. Besides the prepreg studies mentioned above, the out-of-plane deformation was also defined by other studies as a defect of preforming the dry multi-layered fabric before the resin impregnation and investigated to prevent and delay its appearance as an unwanted phenomenon. With the absence of the resin, which plays the 
role of a lubricant, as mentioned previously, the inter-ply friction is more severe in terms of its role in initiating the out-of-plane deformation. That is why wrinkles are more likely to form in multi-ply settings. Lately, Allaoui et al [5][85] investigated experimentally the effects of the fabric/fabric friction on the initiation and the appearance of the defects with multi-layer stacked in a different orientation formed with prism. The choice of geometry was dictated to generate the defects using its highly curved and deep draw shape. Comparing the single layer to the multi-layer setup, the defects on the multi-layered set have a higher magnitude and severity than the single layer. The "wrinkles" here are defined as the out-of-plane deformation that accumulated on all layers. It is then concluded that the blank holders have great effects on inducing or reducing the defects depending on the whole set configuration and it is stated that the orientation of the fabric as a reference to the punch also influences the number and type of defects while working with highly curved shapes. When ply subjects to more defects are placed in the internal position of the stacking, the compaction of the upper ply tends to reduce the defect and prevent its expansion. Moreover, it has been shown that the inter-layer slippage, when it's greater than the unit cell length, has more influence on the increase of the amount and amplitude of the defects than the value of the fabric/fabric friction.

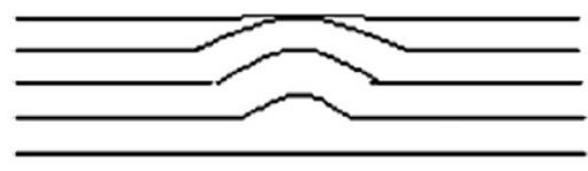

Out of plane deformation - waviness

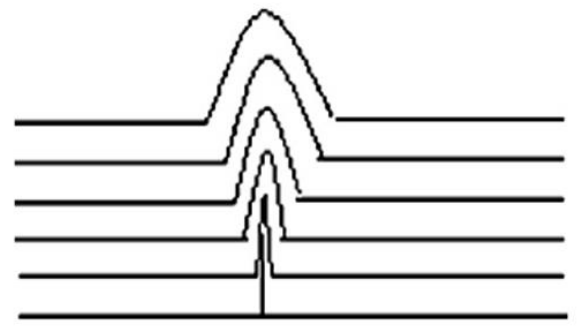

Out of plane deformation - wrinkles
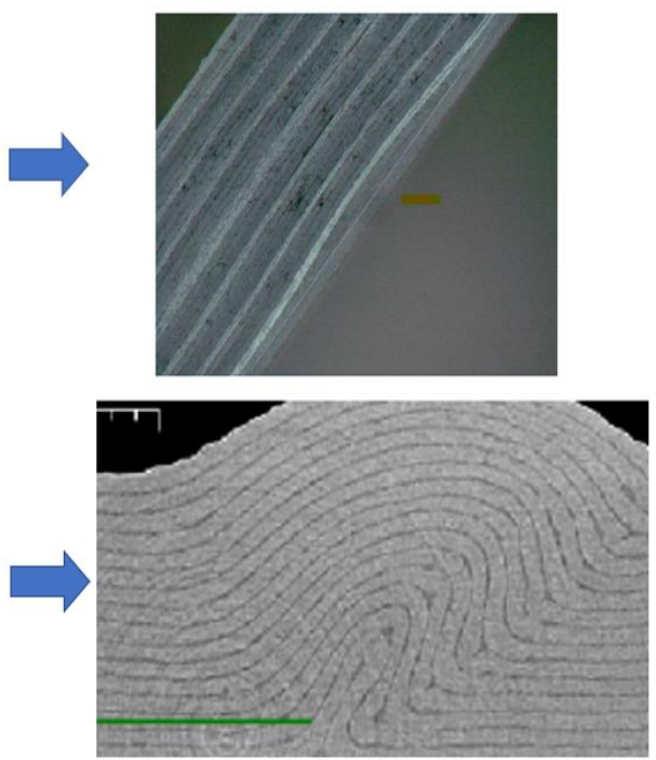

Figure 8: Out of plane deformation a- waviness b- wrinkles [78]

So the appearance and the profile of the out of planes defects are highly influenced by the deformation mode and the stress distribution throughout the plies. Therefore, the occurrence of defects when using blankholders, which apply in plane tension to the fabric throught the applied pressure, differs from the case of diaphragm forming that brings a normal uniform pressure applies on the either or both surfaces of the laminate. With the absence of the in-plane stress to absorb, the undulations transform into wrinkles[86] and 
the yars' in-plane movements and rotations are very limited. This process also comes with a common defect of the bridging due to the low pressure that goes from 0 to 1 Bar [51].

Therefore, some authors developed the concept of preform optimization to delay as much as possible the appearance of the defects or minimize their magnitude. A. Shanwan [87] classified the different preform parameters such as the blank holder pressure and geometry, controlling the fabric /fabric friction by inserting a mat fabric in between and reaching an optimized preforming process by combining multiple solutions. Also, Hao et al. [11], L.S.Liu [88] and H.Shen [89] worked on different geometries (hemisphere, box ...) to determine the influence of the tufting and the density of the stitching on the initiation of the out-of-plane deformation of the multi-layered preforms. Since this defect depends highly on the bending stiffness reinforcing the layers by the stitching leads the wrinkles to turn thinner each time the density of the tufting increases. Molnàr [10] went further to develop a specific stitching path depending on the geometry. One of the original methods to reduce the appearance of out-of-plane deformations was developed by Nosrat et al. [9]. They separated the different layers of plain woven carbon fabric using metal sheets and implanted segments with piezo-electric actuators to reduce the friction that translates into a strain applied on the fabric, which may initiate the appearance of the wrinkle during the forming. They found that by using this technique they eliminated the appearance of wrinkles even the ones that had high magnitude.

\section{b) In-plane deformation:}

The in-plane defects of the single-layer can look similar to the defects on a multilayer set but the mechanisms behind them can vary, so with that, the classification of the 3 types of in-plane defaults put by Hallander [57] applies also on the multi-layer (Fig.04 a-b-c). The in-plane deformation is spotted also in the work of Ó Brádaigh [90] with a type of deformation named "buckling" illustrated in (Fig.9). A thin band of the fiber located at the fabric centerline was forced to slide because it is situated at the diameter of the hemisphere and sharing the same direction. The fiber could not resist the shearing leading to the deformation propagating all along with the sheet and eventually reaching the edges. An identical phenomenon was spotted by De Lucas [80], located where the fiber direction is parallel to the hemisphere's diameter, described as a sliding of the fabric giving it a waved form.

Every noticeable in-plane movement of the fibers or yarns should be investigated because it threatens to play the role of a defect that influences the mechanical properties. One of the most important properties of the composite materials is to conserve the homogeneity of the fiber density and keep a constant fiber/resin volume fractions distribution through all the formed shapes. The earliest studies that concentrated on this aspect were done by Bickerton [91] in 1997, by determining the influence of the shearing angle variation on the volume fraction distribution on different areas of a cone form. The results showed that the fabric draping changes significantly the fiber orientations and the volume fraction distribution. A similar study was done by Koziey [92] about the thickness variation during thermoforming. This variation is due to the typical material 
behavior while forming the sheet is subjected to biaxial stretching that has a major effect on the material distribution considering the strain hardening characteristic of the plastic hence the thickness variation.

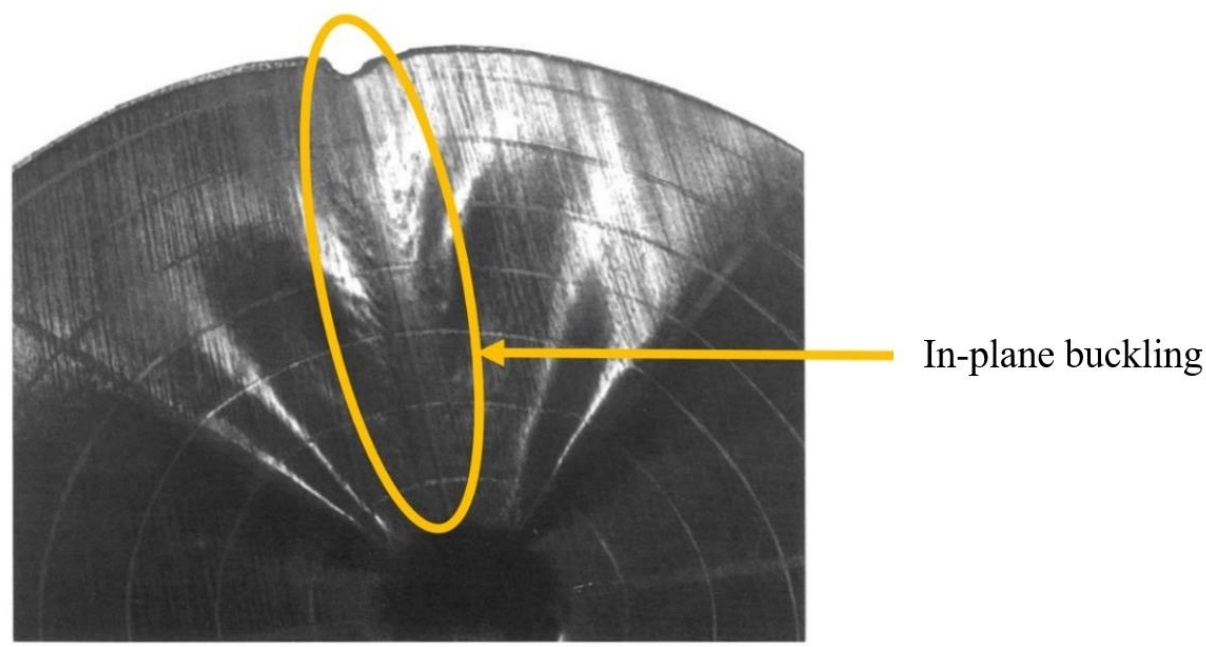

Figure 9: In-plane "buckling "[90]

When the fabric/fabric friction is considerably high and added to the tool/fabric friction, this affects each ply. The pressure applied to the stacking generates the tangential friction loads on each layer, which takes different directions depending on the geometry and the fabric orientation. Nosrat [93] has elaborated a detailed experimental process to determine the onset of the defects depending on some forming settings and configurations such as the layer orientation choice and the normal pressure applied onto the fabric. The number of defects appearing, compared to the single layer, is considerably higher and increasing the relative orientation angle of the ply leads to an increase of the defect's number and intensity. Backed up by the study of Jennifer [94] that showed the importance of the different preforming factors (orientation, speed, the temperature ...) on the inter ply friction behavior in case of the prepreg. Allaoui [95, 96] and Hivet [97] investigated, using a developed device, the friction behavior between layers made of dry reinforcement. They highlighted the importance of understanding this particular behavior, which varies depending on the orientation and that this behavior plays a major role in the initiation of the defects', along with other factors, such as in the geometry details like a small radius that means higher normal forces that counter the forces of the blank holder pressure. Therefore, increases in-plane stress on the fabric lead to in-plane failures in the form of distortion and a disturbance in the arrangement pattern of the fabric. Nosrat concluded that inter-ply friction is crucial to the preform quality and should be reduced to avoid the appearance of in-plane defects. An identical defect is found in Allaoui's study [5, 45], called "weave pattern heterogeneity", where the fabric meso-architecture is impacted and is no longer respects the weaving of the fabric. This heterogeneity is due to the relative weft and warp yarn sliding or slippage leading to a local high or low fiber density [45]. The origin of this default is the difference between the loads in both yarn network directions. The destruction of the 
pattern structure occurs when the frictional tangential forces, generated by the blank holders on one of the yarn directions are higher than the fabric cohesion. This sliding depends strongly on the complexity of that shape generates severe stress due to the in-plane load distribution.

\section{Yarn defects:}

The preforming process affects the structure of the fabric at the macroscopic level and it inevitably goes into the micro and mesoscopic levels that affect the yarns or fiber filaments.

\section{1) Out-of-plane defect}

The "yarn buckling" is when the yarns are subjected to out-of-plane buckling, go out of the plane of the fabric, and hence no longer respect their initial form resulting in local irregularities (Fig.10-a-b). One first study highlighting this mesoscopic defect on the woven fabric experimentally is done by Allaoui et al. [98] (in 2007) with the shaping of interlock reinforcement on complex geometry. The yarn buckling can manifest with or without changing the fabric weaving pattern [45] but being an out-of-plane deformation it alters the thickness of the preform [5] and degrade mechanical properties of the composite material $[99,100]$. This mesoscopic defect manifests when the yarn undergoes stress that forces it to buckle and deform in an out-ofplane curve. The buckling can be induced by a compressive load applied on the yarn in the same direction as the fiber [5] ( longitudinal) (Fig.10-b) or by a bending load of the yarn (Fig.10-a) [5, 45, 65, 101, 102]. The profile of the buckling as the affected area and the amplitude are influenced by the fiber material, the tension, and the meso-architecture of the fabric [103]. Thus for the case of flax woven fabric, that is less heterogeneous than those made of synthetic fiber, these defects can be avoided by combining the optimization of the fabric meso-architecture and the blank-holder pressure [101]. This defect is frequently found in the NCF [79] because the fibers are more likely to deform out-of-plane. Indeed, the notion of yarns does not apply because the NCF consists of two layers linked with stitching, which generate compressive stresses during the shearing of the reinforcement. Consequently, it is the fibers, or a set of fibers, which buckle due to their low rigidity compared to the yarns (made up of several thousand fibers) and the boundary conditions, equivalent to the embedding, imposed by the stitching at short fiber's length preventing their slipping locally

(Fig.10-c). 


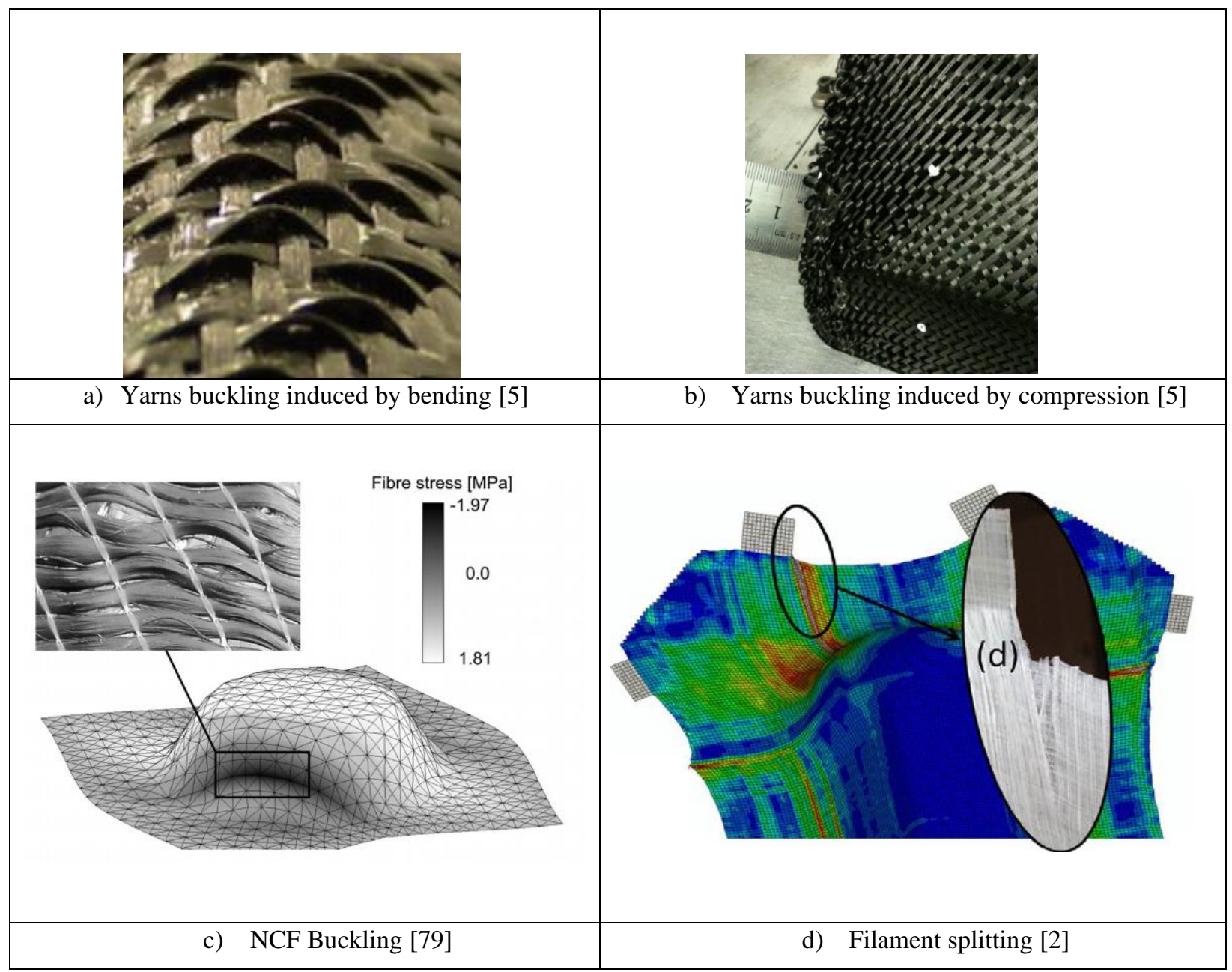

Figure 10: Mesoscopic buckling

\section{2) In-plane defect}

The main reason for this type of defect to manifest is when the in-plane loads are too excessive for the yarn to maintain its form in-plane. It is known that the yarn highest stiffness is following its direction, but in the first case, if the loads are in a different direction of one of the yarns or the filaments, it may lead to the yarn (or filament) splitting [2] when the inter-fiber cohesion can no longer resist the opposing loads (Fig.10-d). In a second scenario, the yarn is subjected to high loads in its direction, which leads to the "fiber rupture ". This can occur when the preforming process is performed under extremely high velocity, like in the case of De Luca [80]'s study, where: the fibers rupture occurred at the bottom ply of the spherical area of a double dome. The same defect was observed by Allaoui et al. [5] during multi-layered preforming, named "fiber breakage“, and was attributed to severe stresses generated by the boundary conditions like the radii of the small curvature of the double-curved geometries, and the pressure exerted by the upper layers on the lower ones. Identical defect identified or as "broken roving's" [93] also occurs at the yarn level for high normal pressure. 


\section{Discussions}

To better understand the defects of the composite preforming, it is important to unify the understanding of each defect's description and on which scale it occurs. Table 1 to 3 is our attempt to summarize most defects found in the literature, which are classified according to the scale on where they appear: the multi-layer, monolayer and yarn defects. For each scale, defects manifest out-of-plane or in-plane. The description provided is an assembly of their common description gived by the authors distinguishing the different vocabulary used to describe the same type of defect. We can conclude from it that the vocabulary referring to composite preforming defects is not yet standardized. This variety in the vocabulary used can be because the authors' use different types of reinforcement (NCF, woven, interlock, unidirectional...), or since some of these defects can be similar but caused by different factors or conditions (buckling, slippage, etc.) or for the fact that the same cause can generate different defects. Ideally, to be able to describe a defect it should be in a reference to the behavior mechanisms and the mode of deformation that caused it to appear. This is not simple to apply since the stress/deformation is under the influence of other parameters such as the details of the preform geometry, the boundary conditions, the fabric structure, the fabric behavior, etc. Then, the fact that the reinforcement is highly heterogeneous, so we have the defects that appear locally and the ones that affect the whole length of the reinforcement. This highlights if defects should be named the same under different scales.

\begin{tabular}{|l|l|l|}
\hline \multicolumn{3}{|c|}{ IV. Mono-layer defects } \\
\hline Defect definition / description & Out of plane deformation \\
\hline $\begin{array}{l}\text { When the fabric deforms in and out } \\
\text { of plane taking the shape of a waved } \\
\text { curve that can vary in length, } \\
\text { number, and magnitude. }\end{array}$ & $\begin{array}{l}\text { Wrinkles }[6-8,22,37-39, \\
41,43-48,95] ; \text { Bucking }[33, \\
34,36,52,104,105]\end{array}$ \\
\hline $\begin{array}{l}\text { When the fabric deforms in an out- } \\
\text { of-plane curved form, identical to the } \\
\text { "wrinkles" mechanism described, the } \\
\text { two sides of the curves will fall, one } \\
\text { on the other, multiplying the } \\
\text { thickness of the fabric locally. }\end{array}$ & Folds $[4,46,48,49]$ \\
\hline
\end{tabular}




\begin{tabular}{|c|c|c|}
\hline $\begin{array}{l}\text { When forming a curved concave } \\
\text { form, the material retreats in a corner } \\
\text { and the fabric is no longer in contact } \\
\text { with the shaping form and stay } \\
\text { suspended mid-air }\end{array}$ & Bridging $[49,50]$ & $\begin{array}{l}\text { Bridging: a pre-defined } \\
\text { term for this } \\
\text { phenomenon }\end{array}$ \\
\hline \multicolumn{3}{|c|}{ In-plane deformation } \\
\hline $\begin{array}{l}\text { 1- The yarn slides from its initial } \\
\text { position to another following its } \\
\text { longitudinal direction. One yarn can } \\
\text { move individually or as a group with } \\
\text { similar or different movements. } \\
\text { 2-When the movement of the yarn is } \\
\text { perpendicular to its direction, it tends } \\
\text { to either slide closer to its } \\
\text { neighboring yarn, resulting in a high- } \\
\text { density area or move further leaving } \\
\text { a low-density area or even gaps. } \\
\text { This defect can occur locally creating } \\
\text { a local in-plane curve or_deviation. }\end{array}$ & $\begin{array}{l}\text { 2- In plane } \\
\text { wrinkles/waviness [48][106]; } \\
\text { Laddering[8]; Gaps[59]; } \\
\text { Sliding [107][63] ; Slippage } \\
\text { [2] ; Weave Pattern } \\
\text { heterogeneity [45] }\end{array}$ & $\begin{array}{l}\text { Slippage } \\
\text { A local in-plane } \\
\text { curved deformation }\end{array}$ \\
\hline $\begin{array}{l}\text { When the shifting of the fiber } \\
\text { position in-plane is randomly } \\
\text { creating an irregular yarns pattern } \\
\text { distribution }\end{array}$ & $\begin{array}{l}\text { In-plane Buckling[7][48]; } \\
\text { Fiber distortion [93] }\end{array}$ & $\begin{array}{l}\text { Slippage: Same defect and causes as slippage (Fig.5- } \\
\text { c) at multiple random rates (Fig.6-a-b). }\end{array}$ \\
\hline
\end{tabular}

Table 1: Summary of the monolayer defects 


\begin{tabular}{|c|c|c|c|}
\hline \multicolumn{4}{|c|}{ Multi-layer defects } \\
\hline \multicolumn{2}{|c|}{ Defect definition / description } & Terms used & Illustrations +Generalized term suggested \\
\hline \multicolumn{4}{|c|}{ Out of plane deformation } \\
\hline \multirow[t]{3}{*}{$\begin{array}{l}\text { Corner } \\
\text { defects } \\
:\end{array}$} & $\begin{array}{l}\text { Having different radii between the } \\
\text { interlayers and the outer layer at the corner } \\
\text { resulting in the inner layer buckling to } \\
\text { cope with the compressive force. }\end{array}$ & $\begin{array}{l}\text { Buckling [66, 70]; } \\
\text { Wrinkles[20, 67, } \\
\text { 108]; Misalignment } \\
\text { or misorientation [30] }\end{array}$ & $\underline{\text { Wrinkles }}$ \\
\hline & $\begin{array}{l}\text { Different radii induce tensile forces on the } \\
\text { outer layers forcing them to move to the } \\
\text { internal layer and squeezing the resin out. } \\
\text { So, we have fabric piling at the inter part } \\
\text { and resin-rich are at the outer part. }\end{array}$ & $\begin{array}{l}\text { Resin squeezing } \\
{[70][71]}\end{array}$ & Resin squeezing \\
\hline & $\begin{array}{l}\text { The thickness is at its minimum at the } \\
\text { corner tip due to the interlayer friction } \\
\text { making it difficult for the plies to inter slip. }\end{array}$ & $\begin{array}{l}\text { Thickness reduction } \\
{[75,76]}\end{array}$ & $\underline{\text { Thickness reduction }}$ \\
\hline \multicolumn{2}{|c|}{$\begin{array}{l}\text { The stack of the fabric changes its shape to an out- } \\
\text { of-plane curve. This deformation can affect all the } \\
\text { layers or only a certain group and not the rest of the } \\
\text { plies. }\end{array}$} & $\begin{array}{l}\text { Wrinkles[3, 5, 9-12, } \\
57,78,84,88][109] \\
\text { Waviness ; Shear } \\
\text { buckling[90] }\end{array}$ & Wrinkles: The most frequented use of the term \\
\hline \multicolumn{2}{|c|}{$\begin{array}{l}\text { After the curve of the wrinkles is formed, normal } \\
\text { forces applied on the stack of layers can result in the } \\
\text { curve sides collapsing on the other, multiplying the } \\
\text { thickness of the local area depending on the number } \\
\text { of layers folded. }\end{array}$} & Folds [44] [81] & $\underline{\text { Folds }}$ \\
\hline
\end{tabular}




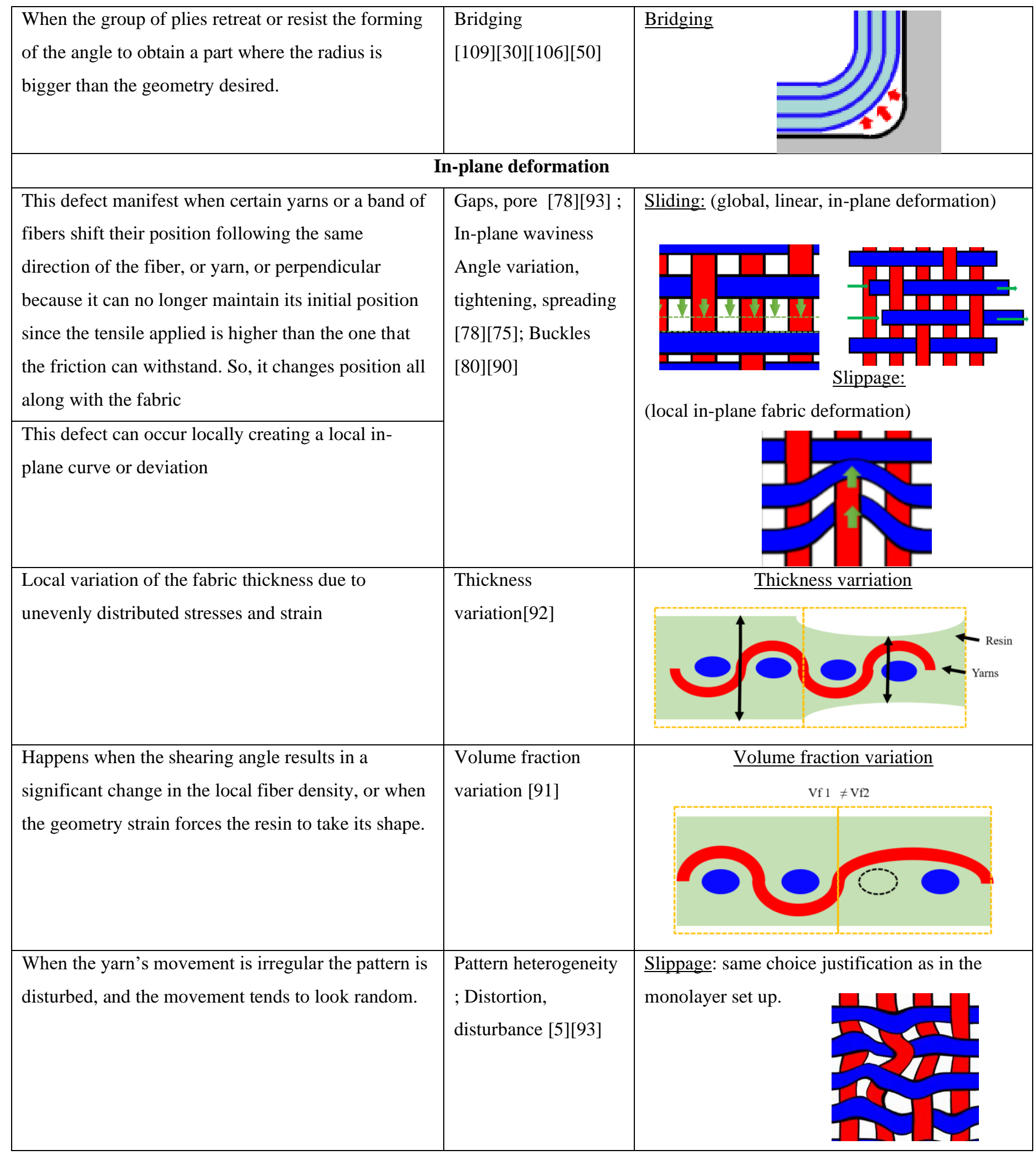

Table 2: Summary of the multi-layered defects. 


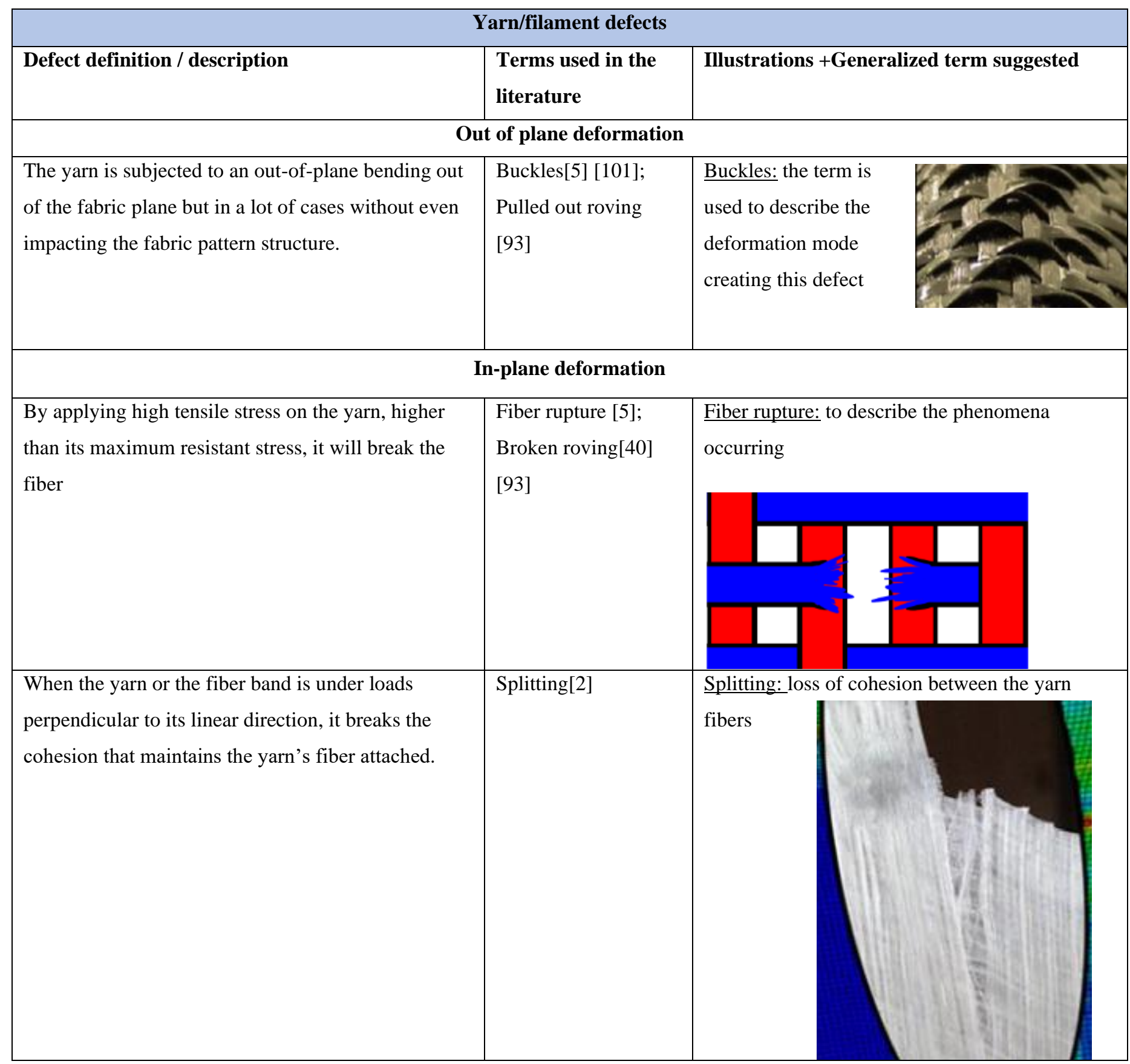

Table 3: Summary of the mesoscopic defects.

The second aspect to look at is when the deformation and disturbance are considered a defect. The shearing for example is considered a natural behavior during preforming for the fabric to adapt to the shape of the part, but there are some areas where the high shearing is considered a defect as well as the variation in volume fraction of fiber which results therefrom. The same goes for the wrinkles, the sliding, etc., which are 
considered as a defects the moment that they are visible usually with the naked eye without considering a measurable threshold.. If we consider the case of a wrinkle is a form of out-of-plane bending deformation and thus a fabric behavior. Starting from which threshold magnitude we can consider it as a defect and not a deformation? This magnitude should be a function of the fabric thickness but while ideally considering its criticality on the composite mechanical behavior and its effect on the further steps of the process (resin injection for example) where the wrinkles can disappear due to the compression during the fabrics compaction between process tools. The same remark can be made to other defects like "sliding", "gap", "slippage", ... where the limit to consider these phenomena as defects could be related to the fabric meso-architecture parameters (yarn width, unit cell length, ...) and its criticality on the composite behavior.

Many studies have been concentrating on the defects located at a corner. The vocabulary used by authors like "wrinkles", "resin squeezing" and "thickness reduction" (Tab.2). These distinctive terms are easily identified for being a defect of the corner.

The defects referred to as a "thickness and volume fraction variation " are more likely to describe the outcome of a defect since they are a way to measure the physical impact of a defect (Tab.2), where they can be the result of many different types of defects manifesting under a different mechanism.

Noticing that the term "buckling " has been used frequently to describe different defects in different scales multi-layers, mono-layers and even at the yarn scale, which is understandable because "buckling" here refers to the deformation mode that caused all these defects, either in-plane or out-of-plane, so to avoid the confusion, our choice was to use it on the out of plane yarn buckling since the only term that has been used to describe it.

The method that we used to identify each defect started by classifying the scale in which it occurs, then deciding them into in-plane and out-of-plane to avoid any confusion between defects with the same name and in different scales and than to attribute names according to defect we chose. We favored the terms that they are frequently used, which are more assertive describing the defect to lessen the chances of a mix-up, the defects having the same deformation outcome and causes are named the same.

\section{Conclusion}

Understanding the preforming defects to obtain non-defective parts, is a major issue for the extension of the use of composites materials in several industries' sectors. For this purpose, it is necessary to understand the deformation mechanisms and the material's behavior in response, and master the many factors that play a role in the initiation of defects. There is a diversity in the work done by the researches until now, a variation in investigating these factors and proposing a solution to predict their appearance and ways to suppress them. This diversity created a difference in the way authors have been defining and identifying these defects and even the vocabulary of reference terms. 
In this review, we started by identifying the defects listed in the literature and classified them according to the scale where they appear, i.e. multi-layers, monolayer, and yarns. Each of those defects is characterized by their type of deformation being out or in-plane. We started by identifying each defect searching for the similarities in the way different authors' definitions and interpretations of the manifestation mechanisms and the cause of their appearance. The cause of these defects, which are detailed for each, can be due to the material's behavior due to the deformation mode they undergo, the preforming setup or the geometry characteristics we are aiming for, or the process parameter is chosen.

After studying the defects defined by authors we concluded that authors have used different ways to identify the defects. Some of them referred to the cause of the defect and the mechanisms behind their appearance, others referred to the type of deformation created by these mechanisms and others used terms to describe the outcome of the deformation. So, we can find a defect with different definitions and terms while they are describing the same defect, while in other cases different defect was referred to by the same term.

Our attempt to put together a way to unite the vocabulary used to name each defect is not the same from an author to another, we summarised a definition that helps identify the defects and proposed a term of reference. Having a solid definition and vocabulary will avoid any confusion in the future in the community when working on the defects.

This can be the first contribution to converge toward a composite forming defects manual that would make it possible to work on the same basis for the numerous studies in progress or to come which relate to several aspects related to formatting defects such as: a more detailed understanding of the mechanisms involved during the appearance of these defects, the evaluation of the effect induced on the performance of the composite material as well as the establishment of criteria taking into account these two aspects and which would be implemented in the numeriacal codes.

All of this knowledge would make it possible to increase the mastery of composites processes and therefore their use in different industrial sctors.

\section{Conflict of Interest:}

The authors declare that they have no conflict of interest.

\section{References}

1. Paul SK (2013) Theoretical analysis of strain- and stress-based forming limit diagrams. J Strain Anal Eng Des 48:177-188. https://doi.org/10.1177/0309324712468524

2. Harrison P, Gomes R, Curado-Correia N (2013) Press forming a 0/90 cross-ply advanced thermoplastic composite using the double-dome benchmark geometry. Compos Part A Appl Sci Manuf 54:56-69. https://doi.org/10.1016/j.compositesa.2013.06.014

3. Wang P, Hamila N, Boisse P (2013) Thermoforming simulation of multilayer composites with continuous fibres and thermoplastic matrix. Compos Part B Eng 52:127-136. https://doi.org/10.1016/j.compositesb.2013.03.045 
4. Skordos AA, Monroy Aceves C, Sutcliffe MPF (2007) A simplified rate dependent model of forming and wrinkling of pre-impregnated woven composites. Compos Part A Appl Sci Manuf 38:1318-1330.

https://doi.org/10.1016/j.compositesa.2006.11.005

5. Allaoui S, Cellard C, Hivet G (2015) Effect of inter-ply sliding on the quality of multilayer interlock dry fabric preforms. Compos Part A Appl Sci Manuf 68:336-345. https://doi.org/10.1016/j.compositesa.2014.10.017

6. Allaoui S, Boisse P, Chatel S, et al (2011) Experimental and numerical analyses of textile reinforcement forming of a tetrahedral shape. Compos Part A Appl Sci Manuf 42:612-622. https://doi.org/10.1016/j.compositesa.2011.02.001

7. Lee JS, Hong SJ, Yu WR, Kang TJ (2007) The effect of blank holder force on the stamp forming behavior of non-crimp fabric with a chain stitch. Compos Sci Technol 67:357-366.

https://doi.org/10.1016/j.compscitech.2006.09.009

8. Turk MA, Vermes B, Thompson AJ, et al (2020) Mitigating forming defects by local modification of dry preforms Mark. Compos Part A Appl Sci Manuf 128:105643. https://doi.org/10.1016/j.compositesa.2019.105643

9. Nosrat Nezami F, Gereke T, Cherif C (2017) Active forming manipulation of composite reinforcements for the suppression of forming defects. Compos Part A Appl Sci Manuf 99:94-101. https://doi.org/10.1016/j.compositesa.2017.04.011

10. Molnár P, Ogale A, Lahr R, Mitschang P (2007) Influence of drapability by using stitching technology to reduce fabric deformation and shear during thermoforming. Compos Sci Technol 67:3386-3393.

https://doi.org/10.1016/j.compscitech.2007.03.022

11. Hao S, Wang P, Legrand X, et al (2019) Influence of the tufting pattern on the formability of tufted multi-layered preforms. Compos Struct 228:111356. https://doi.org/10.1016/j.compstruct.2019.111356

12. Haorong LI, Gutowski T (1997) Chapter 11 The forming of thermoset composites. Compos Mater Ser 11:441472. https://doi.org/10.1016/S0927-0108(97)80013-6

13. Viisainen J V., Hosseini A, Sutcliffe MPF (2021) Experimental investigation, using 3D digital image correlation, into the effect of component geometry on the wrinkling behaviour and the wrinkling mechanisms of a biaxial NCF during preforming. Compos Part A Appl Sci Manuf 142:106248.

https://doi.org/10.1016/j.compositesa.2020.106248

14. El Said B, Green S, Hallett SR (2014) Kinematic modelling of 3D woven fabric deformation for structural scale features. Compos Part A Appl Sci Manuf 57:95-107. https://doi.org/10.1016/j.compositesa.2013.11.006

15. Tavana R, Najar SS, Abadi MT, Sedighi M (2013) Meso/macro-scale finite element model for forming process of woven fabric reinforcements. J Compos Mater 47:2075-2085. https://doi.org/10.1177/0021998312454034

16. Sherwood JA, Fetfatsidis KA, Gorczyca JL, Berger L (2012) Fabric thermostamping in polymer matrix composites. Woodhead Publishing Limited

17. Dörr D, Joppich T, Schirmaier F, et al (2016) A Method for Validation of Finite Element Forming Simulation On Basis of a Pointwise Comparison of Distance and Curvature. 170011:. https://doi.org/10.1063/1.4963567

18. Dörr D, Brymerski W, Ropers S, et al (2017) A Benchmark Study of Finite Element Codes for Forming Simulation of Thermoplastic UD-Tapes. Procedia CIRP 66:101-106. https://doi.org/10.1016/j.procir.2017.03.223

19. Boisse P, Hamila N, Vidal-sallé E, Dumont F (2011) Simulation of wrinkling during textile composite reinforcement forming. Influence of tensile, in-plane shear and bending stiffnesses. Compos Sci Technol 71:683-692. https://doi.org/10.1016/j.compscitech.2011.01.011 
20. Hallett SR, Belnoue JPH, Nixon-Pearson OJ, et al (2016) Understanding and prediction of fibre waviness defect generation. Proc Am Soc Compos - 31st Tech Conf ASC 2016

21. Khan MA, Mabrouki T, Vidal-Sallé E, Boisse P (2010) Numerical and experimental analyses of woven composite reinforcement forming using a hypoelastic behaviour. Application to the double dome benchmark. $\mathrm{J}$ Mater Process Technol 210:378-388. https://doi.org/10.1016/j.jmatprotec.2009.09.027

22. Bloom LD, Wang J, Potter KD (2013) Damage progression and defect sensitivity: An experimental study of representative wrinkles in tension. Compos Part B Eng 45:449-458.

https://doi.org/10.1016/j.compositesb.2012.05.021

23. El-Hajjar RF, Petersen DR (2011) Gaussian function characterization of unnotched tension behavior in a carbon/epoxy composite containing localized fiber waviness. Compos Struct 93:2400-2408.

https://doi.org/10.1016/j.compstruct.2011.03.029

24. Wang J, Potter KD, Hazra K, Wisnom MR (2012) Experimental fabrication and characterization of out-of-plane fiber waviness in continuous fiber-reinforced composites. J Compos Mater 46:2041-2053. https://doi.org/10.1177/0021998311429877

25. Mukhopadhyay S, Jones MI, Hallett SR (2015) Tensile failure of laminates containing an embedded wrinkle; numerical and experimental study. Compos Part A Appl Sci Manuf 77:219-228.

https://doi.org/10.1016/j.compositesa.2015.07.007

26. Xu X, Jones MI, Ali H, et al (2020) Effect of out-of-plane wrinkles in curved multi-directional carbon/epoxy laminates. Compos Sci Technol 197:108282. https://doi.org/10.1016/j.compscitech.2020.108282

27. Xie N, Smith RA, Mukhopadhyay S, Hallett SR (2018) A numerical study on the influence of composite wrinkle defect geometry on compressive strength. Mater Des 140:7-20. https://doi.org/10.1016/j.matdes.2017.11.034

28. Mukhopadhyay S, Nixon-Pearson OJ, Hallett SR (2018) An experimental and numerical study on fatigue damage development in laminates containing embedded wrinkle defects. Int J Fatigue 107:1-12. https://doi.org/10.1016/j.ijfatigue.2017.10.008

29. Nikishkov Y, Makeev A, Seon G (2013) Progressive fatigue damage simulation method for composites. Int J Fatigue 48:266-279. https://doi.org/10.1016/j.ijfatigue.2012.11.005

30. Potter K, Khan B, Wisnom M, et al (2008) Variability, fibre waviness and misalignment in the determination of the properties of composite materials and structures. Compos Part A Appl Sci Manuf 39:1343-1354.

https://doi.org/10.1016/j.compositesa.2008.04.016

31. Fedulov BN, Antonov FK, Safonov AA, et al (2015) Influence of fibre misalignment and voids on composite laminate strength. J Compos Mater 49:2887-2896. https://doi.org/10.1177/0021998314557533

32. Creech G, Pickett AK (2006) Meso-modelling of Non-crimp Fabric composites for coupled drape and failure analysis. J Mater Sci 41:6725-6736. https://doi.org/10.1007/s10853-006-0213-6

33. Tam AS, Gutowski TG (1990) The kinematics for forming ideal aligned fibre composites into complex shapes. Compos Manuf 1:219-228. https://doi.org/10.1016/0956-7143(90)90044-W

34. Christie GR, Collins IF, Bhattacharyya D (1995) Out-of-plane buckling of fiber-reinforced thermoplastic sheets under homogeneous biaxial conditions. J Appl Mech Trans ASME 62:834-840.

https://doi.org/10.1115/1.2896008

35. Pavan Kumar J, Uday Kumar R, Ramakrishna B, et al (2018) Formability of sheet metals - A review. IOP Conf Ser Mater Sci Eng 455:. https://doi.org/10.1088/1757-899X/455/1/012081 
36. Yu JZ, Cai Z, Ko FK (1994) Formability of textile preforms for composite applications. Part 1: Characterization experiments. Compos Manuf 5:113-122. https://doi.org/10.1016/0956-7143(94)90062-0

37. Mohammed U, Lekakou C, Bader MG (2000) Experimental studies and analysis of the draping of woven fabrics. Compos Part A Appl Sci Manuf 31:1409-1420. https://doi.org/10.1016/S1359-835X(00)00080-4

38. Boisse P, Gasser A, Hivet G (2001) Analysis of the mechanical behaviour : determination of the biaxial tensiostrain surfaces and their use in forming simulations. Exp Mech 32:260-269

39. Zouari B, Daniel J, Boisse P (2006) A woven reinforcement forming simulation method . Influence of the shear stiffness To cite this version : HAL Id : hal-00081069 A woven reinforcement forming simulation method . Influence of the shear stiffness

40. Komeili M, Milani AS (2016) On effect of shear-tension coupling in forming simulation of woven fabric reinforcements. Compos Part B Eng 99:17-29. https://doi.org/10.1016/j.compositesb.2016.05.004

41. Boisse P, Hamila N, Vidal-Sallé E, Dumont F (2011) Simulation of wrinkling during textile composite reinforcement forming. Influence of tensile, in-plane shear and bending stiffnesses. Compos Sci Technol 71:683692. https://doi.org/10.1016/j.compscitech.2011.01.011

42. de Bilbao E, Soulat D, Hivet G, Gasser A (2010) Experimental Study of Bending Behaviour of Reinforcements. Exp Mech 50:333-351. https://doi.org/10.1007/s11340-009-9234-9

43. Boisse P, Colmars J, Hamila N, et al (2018) Bending and wrinkling of composite fiber preforms and prepregs. A review and new developments in the draping simulations. Compos Part B Eng 141:234-249.

https://doi.org/10.1016/j.compositesb.2017.12.061

44. Dangora LM, Mitchell CJ, Sherwood JA (2015) Predictive model for the detection of out-of-plane defects formed during textile-composite manufacture. Compos Part A Appl Sci Manuf 78:102-112. https://doi.org/10.1016/j.compositesa.2015.07.011

45. Allaoui S, Hivet G, Soulat D, et al (2014) Experimental preforming of highly double curved shapes with a case corner using an interlock reinforcement. Int J Mater Form 7:155-165. https://doi.org/10.1007/s12289-012-1116-5

46. Long AC, Rudd CD (1994) A simulation of reinforcement deformation during the production of preforms for liquid moulding processes. Proc Inst Mech Eng Part B J Eng Manuf 208:269-278.

https://doi.org/10.1243/PIME_PROC_1994_208_088_02

47. Wang J, Paton R, Page JR (1999) Draping of woven fabric preforms and prepregs for production of polymer composite components. Compos Part A Appl Sci Manuf 30:757-765. https://doi.org/10.1016/S1359-

835X(98)00187-0

48. Böhler P, Härtel F, Middendorf P (2013) Identification of forming limits for unidirectional carbon textiles in reality and mesoscopic simulationy and mesoscopic simulation. Key Eng Mater 554-557:423-432.

https://doi.org/10.4028/www.scientific.net/KEM.554-557.423

49. Middendorf P PROCESS PARAMETER STUDIES AND COMPARISON OF. 7577-7587

50. Alshahrani H, Hojjati M (2017) Experimental and numerical investigations on formability of out-of-autoclave thermoset prepreg using a double diaphragm process. Compos Part A Appl Sci Manuf 101:199-214. https://doi.org/10.1016/j.compositesa.2017.06.021

51. Chen S, McGregor OPL, Endruweit A, et al (2017) Double diaphragm forming simulation for complex composite structures. Compos Part A Appl Sci Manuf 95:346-358.

https://doi.org/10.1016/j.compositesa.2017.01.017 
52. ÓBrádaigh CM, McGuinness GB, Pipes RB (1993) Numerical analysis of stresses and deformations in composite materials sheet forming: central indentation of a circular sheet. Compos Manuf 4:67-83.

https://doi.org/10.1016/0956-7143(93)90074-I

53. Fetfatsidis KA, Jauffrès D, Sherwood JA, Chen J (2013) Characterization of the tool/fabric and fabric/fabric friction for woven-fabric composites during the thermostamping process. Int J Mater Form 6:209-221. https://doi.org/10.1007/s12289-011-1072-5

54. Harrison P, ten Thije R, Akkerman R, Long AC (2010) Characterisation and modelling friction at the tool-ply interface for thermoplastic woven composites. 1-2

55. ten Thije RHW, Akkerman R, van der Meer L, Ubbink MP (2008) Tool-ply friction in thermoplastic composite forming. Int J Mater Form 1:953-956. https://doi.org/10.1007/s12289-008-0215-9

56. Laroche D V-KT (1993) Forming of Woven Fabric Composites. 1825-1839

57. Hallander P, Akermo M, Mattei C, et al (2013) An experimental study of mechanisms behind wrinkle development during forming of composite laminates. Compos Part A Appl Sci Manuf 50:54-64. https://doi.org/10.1016/j.compositesa.2013.03.013

58. Thor M, Sause MGR, Hinterhölzl RM (2020) Mechanisms of Origin and Classification of Out-of-Plane Fiber Waviness in Composite Materials-A Review. J Compos Sci 4:130. https://doi.org/10.3390/jcs4030130

59. Li L, Zhao Y, Zhao X, et al (2015) The effect of preforming quality on the permeability of non-crimp fabrics and the mechanical properties of their composites. ICCM Int Conf Compos Mater 2015-July:19-24

60. Bel S, Boisse P, Dumont F (2012) Analyses of the deformation mechanisms of non-crimp fabric composite reinforcements during preforming. Appl Compos Mater 19:513-528. https://doi.org/10.1007/s10443-011-9207-X

61. Bel S, Hamila N, Boisse P, Dumont F (2012) Finite element model for NCF composite reinforcement preforming: Importance of inter-ply sliding. Compos Part A Appl Sci Manuf 43:2269-2277.

https://doi.org/10.1016/j.compositesa.2012.08.005

62. Daniel J-L, Soulat D, Dumont F, et al (2003) Forming of a Very Unbalanced Fabric Experiment and Simulation. Int J Form Process 6:465-480. https://doi.org/10.3166/ijfp.6.465-480

63. Gatouillat S, Bareggi A, Vidal-Sallé E, Boisse P (2013) Meso modelling for composite preform shaping Simulation of the loss of cohesion of the woven fibre network. Compos Part A Appl Sci Manuf 54:135-144. https://doi.org/10.1016/j.compositesa.2013.07.010

64. Boisse P, Hamila N, Madeo A (2016) Modelling the development of defects during composite reinforcements and prepreg forming. Philos Trans R Soc A Math Phys Eng Sci 374:. https://doi.org/10.1098/rsta.2015.0269

65. Tephany C, Gillibert J, Ouagne P, et al (2016) Development of an experimental bench to reproduce the tow buckling defect appearing during the complex shape forming of structural flax based woven composite reinforcements. Compos Part A Appl Sci Manuf 81:22-33. https://doi.org/10.1016/j.compositesa.2015.10.011

66. Tam AS, Gutowski TG (1989) Ply-Slip During the Forming of Thermoplastic Composite Parts. J Compos Mater 23:587-605. https://doi.org/10.1177/002199838902300604

67. Dodwell TJ, Butler R, Hunt GW (2014) Out-of-plane ply wrinkling defects during consolidation over an external radius. Compos Sci Technol 105:151-159. https://doi.org/10.1016/j.compscitech.2014.10.007

68. Belnoue JPH, Nixon-Pearson OJ, Thompson AJ, et al (2018) Consolidation-driven defect generation in thick composite parts. J Manuf Sci Eng Trans ASME 140:. https://doi.org/10.1115/1.4039555

69. Rashidi A, Belnoue JPH, Thompson AJ, et al (2021) Consolidation-driven wrinkling in carbon/epoxy woven 
fabric prepregs: An experimental and numerical study. Compos Part A Appl Sci Manuf 143:106298.

https://doi.org/10.1016/j.compositesa.2021.106298

70. Cattanach JB, Guff G, Cogswell FN THE PROCESSING OF THERMOPLASTICS CONTAINING HIGH. 345362

71. Jerpdal L, Åkermo M, Ståhlberg D, Herzig A (2018) Process induced shape distortions of self-reinforced poly(ethylene terephthalate) composites. Compos Struct 193:29-34.

https://doi.org/10.1016/j.compstruct.2018.03.038

72. Hubert P, Poursartip A (2001) Aspects of the compaction of composite angle laminates: an experimental investigation. J Compos Mater 35:2-26. https://doi.org/10.1106/X8D7-PR9V-U6F2-0JEK

73. Levy A, Hubert P (2019) Vacuum-bagged composite laminate forming processes: Predicting thickness deviation in complex shapes. Compos Part A Appl Sci Manuf 126:105568.

https://doi.org/10.1016/j.compositesa.2019.105568

74. Netzel C, Mordasini A, Schubert J, et al (2021) An experimental study of defect evolution in corners by autoclave processing of prepreg material. Compos Part A Appl Sci Manuf 144:106348.

https://doi.org/10.1016/j.compositesa.2021.106348

75. Hallander P, Sjölander J, Petersson M, Åkermo M (2016) Interface manipulation towards wrinkle-free forming of stacked UD prepreg layers. Compos Part A Appl Sci Manuf 90:340-348.

https://doi.org/10.1016/j.compositesa.2016.07.013

76. Bickerton S, Sozer EM, Graham PJ, Advani SG (2000) Fabric structure and mold curvature effects on preform permeability and mold filling in the RTM process. Part I. Experiments. Compos Part A Appl Sci Manuf 31:423438. https://doi.org/10.1016/S1359-835X(99)00087-1

77. Pierce RS, Falzon BG, Thompson MC (2017) A multi-physics process model for simulating the manufacture of resin-infused composite aerostructures. Compos Sci Technol 149:269-279.

https://doi.org/10.1016/j.compscitech.2017.07.003

78. Hallander P, Sjölander J, Åkermo M (2015) Composites : Part A Forming induced wrinkling of composite laminates with mixed ply material properties ; an experimental study. Compos PART A 78:234-245.

https://doi.org/10.1016/j.compositesa.2015.08.025

79. Thije RHW, Loendersloot R, Akkerman R (2005) Drape simulation of non-crimp fabrics. 8-11

80. De Luca P, Lefébure P, Pickett AK (1998) Numerical and experimental investigation of some press forming parameters of two fibre reinforced thermoplastics: APC2-AS4 and PEI-CETEX. Compos Part A Appl Sci Manuf 29:101-110. https://doi.org/10.1016/S1359-835X(97)00060-2

81. ten Thije RHW, Akkerman R (2009) A multi-layer triangular membrane finite element for the forming simulation of laminated composites. Compos Part A Appl Sci Manuf 40:739-753.

https://doi.org/10.1016/j.compositesa.2009.03.004

82. Boisse P, Huang J, Guzman-Maldonado E (2021) Analysis and modeling of wrinkling in composite forming. J Compos Sci 5:1-16. https://doi.org/10.3390/jcs5030081

83. Huang J, Boisse P, Hamila N, Zhu Y (2020) Simulation of wrinkling during bending of composite reinforcement laminates. Materials (Basel) 13:. https://doi.org/10.3390/ma13102374

84. Wang P, Hamila N, Pineau P, Boisse P (2014) Thermomechanical analysis of thermoplastic composite prepregs using bias-extension test. J Thermoplast Compos Mater 27:679-698. https://doi.org/10.1177/0892705712454289 
85. Allaoui S, Hivet G, Cellard C (2015) Inter-ply friction effect on the forming result of multi-layered composite. Key Eng Mater 651-653:381-386. https://doi.org/10.4028/www.scientific.net/KEM.651-653.381

86. Thompson AJ, Belnoue JPH, Hallett SR (2020) Modelling defect formation in textiles during the double diaphragm forming process. Compos Part B Eng 202:108357. https://doi.org/10.1016/j.compositesb.2020.108357

87. Shanwan A, Allaoui S (2019) Different experimental ways to minimize the preforming defects of multi-layered interlock dry fabric. Int J Mater Form 12:69-78. https://doi.org/10.1007/s12289-018-1407-6

88. Liu LS, Zhang T, Wang P, et al (2015) Influence of the tufting yarns on formability of tufted 3-Dimensional composite reinforcement. Compos Part A Appl Sci Manuf 78:403-411.

https://doi.org/10.1016/j.compositesa.2015.07.014

89. Shen H, Wang P, Legrand X, Liu L (2019) Characterisation and optimisation of wrinkling during the forming of tufted three-dimensional composite preforms. Compos Part A Appl Sci Manuf 127:105651. https://doi.org/10.1016/j.compositesa.2019.105651

90. Ó Brádaigh CM, McGuinness GB, McEntee SP (1997) Chapter 7 Implicit finite element modelling of composites sheet forming processes. Compos Mater Ser 11:247-322. https://doi.org/10.1016/S0927-0108(97)80009-4

91. Bickerton S, Šimáček P, Guglielmi SE, Advani SG (1997) Investigation of draping and its effects on the mold filling process during manufacturing of a compound curved composite part. Compos Part A Appl Sci Manuf 28:801-816. https://doi.org/10.1016/S1359-835X(97)00033-X

92. Koziey BL, Ghafur MO, Vlachopoulos J, Mirza FA (1997) Chapter 3 Computer simulation of thermoforming. Compos Mater Ser 11:75-89. https://doi.org/10.1016/S0927-0108(97)80005-7

93. Nosrat Nezami F, Gereke T, Cherif C (2016) Analyses of interaction mechanisms during forming of multilayer carbon woven fabrics for composite applications. Compos Part A Appl Sci Manuf 84:406-416.

https://doi.org/10.1016/j.compositesa.2016.02.023

94. Gorczyca-Cole JL, Sherwood JA, Chen J (2007) A friction model for thermostamping commingled glasspolypropylene woven fabrics. Compos Part A Appl Sci Manuf 38:393-406.

https://doi.org/10.1016/j.compositesa.2006.03.006

95. (2012) Influence of the dry woven fabrics meso-structure on fabric / fabric contact behavior. https://doi.org/10.1177/0021998311424627

96. Allaoui S, Hivet G, Billoët JL (2009) Experimental analysis of the contact between layers of dry fabrics. Int J Mater Form 2:209-212. https://doi.org/10.1007/s12289-009-0555-0

97. Hivet G, Allaoui S, Cam BT, et al (2012) Design and Potentiality of an Apparatus for Measuring Yarn/Yarn and Fabric/Fabric Friction. Exp Mech 52:1123-1136. https://doi.org/10.1007/s11340-011-9566-0

98. Allaoui S (2007) Integrated Tool for Simulation of Textile Composites

99. Kacimi B, Djebbar A, Allaoui S (2019) Effect of reinforcement shear and mesoscopic defects on the low velocity impact behavior of a GFRP

100. Shanwan A, Cruanes C, Allaoui S, et al (2020) GFRP MECHANICAL BEHAVIOUR INDUCED BY A MESOSCOPIC SHAPING DEFECT To cite this version : HAL Id : hal-02481013

101. Ouagne P, Soulat D, Moothoo J, et al (2013) Complex shape forming of a flax woven fabric; Analysis of the tow buckling and misalignment defect. Compos Part A Appl Sci Manuf 51:1-10.

https://doi.org/10.1016/j.compositesa.2013.03.017

102. Iwata A, Inoue T, Naouar N, et al (2019) Coupled meso-macro simulation of woven fabric local deformation 
during draping. Compos Part A Appl Sci Manuf 118:267-280. https://doi.org/10.1016/j.compositesa.2019.01.004

103. Salem MM, De Luycker E, Fazzini M, Ouagne P (2019) Experimental, analytical and numerical investigation to prevent the tow buckling defect during fabric forming. Compos Part A Appl Sci Manuf 125:105567. https://doi.org/10.1016/j.compositesa.2019.105567

104. Hull BD, Rogers TG, Spencer AJM (1991) Theory of fibre buckling and wrinkling in shear flows of fibrereinforced composites. Compos Manuf 2:185-191. https://doi.org/10.1016/0956-7143(91)90138-7

105. Cai Z, Gutowski T (1992) The 3-D Deformation Behavior of a Lubricated Fiber Bundle. J Compos Mater 26:1207-1237. https://doi.org/10.1177/002199839202600808

106. Lightfoot JS, Wisnom MR, Potter K (2013) Defects in woven preforms: Formation mechanisms and the effects of laminate design and layup protocol. Compos Part A Appl Sci Manuf 51:99-107.

https://doi.org/10.1016/j.compositesa.2013.04.004

107. Labanieh AR, Garnier C, Ouagne P, et al (2018) Intra-ply yarn sliding defect in hemisphere preforming of a woven preform. Compos Part A Appl Sci Manuf 107:432-446.

https://doi.org/10.1016/j.compositesa.2018.01.018

108. Sjölander J, Hallander P, Åkermo M (2016) Forming induced wrinkling of composite laminates: A numerical study on wrinkling mechanisms. Compos Part A Appl Sci Manuf 81:41-51.

https://doi.org/10.1016/j.compositesa.2015.10.012

109. Lightfoot JS, Wisnom MR, Potter K (2013) A new mechanism for the formation of ply wrinkles due to shear between plies. Compos Part A Appl Sci Manuf 49:139-147. https://doi.org/10.1016/j.compositesa.2013.03.002 